\title{
Comparison of functional diversity of two Alaskan Arctic shelf epibenthic communities
}

\author{
Lauren Sutton $^{1, *}$, Katrin Iken ${ }^{1}$, Bodil A. Bluhm ${ }^{2}$, Franz J. Mueter ${ }^{1}$ \\ ${ }^{1}$ College of Fisheries and Ocean Sciences, University of Alaska Fairbanks, 905 N. Koyukuk Dr., Fairbanks, Alaska 99775, USA \\ ${ }^{2}$ Department of Arctic and Marine Biology, UiT - The Arctic University of Norway, PO Box 6050 Langnes, 9037 Tromsø, Norway
}

ABSTRACT: Alaskan Arctic shelf communities are currently experiencing dramatic changes that will likely affect ecosystem functioning of Arctic marine benthic communities. Here, functional diversity based on biological traits was used to assess differences and similarities in ecosystem functioning between 2 shelf systems that are geographically close but vary in many environmental influences: the Arctic Beaufort and Chukchi Sea epibenthic communities. We hypothesized that (1) patterns of functional composition and diversity metrics reflect patterns in taxonomic composition and diversity metrics in these 2 shelf communities; and (2) patterns in functional diversity metrics are distinct between the 2 shelves. We evaluated 9 biological traits (body form, body size, feeding habit, fragility, larval development, living habit, movement, reproductive strategy, sociability) for 327 taxa in 2014 and 2015. For each trait, multiple modalities (specific expressions within a trait) were considered. Patterns in functional diversity metrics on both shelves reflected those in taxonomic diversity metrics. However, shelf communities were more similar in functional- than in taxonomic composition. Beaufort Sea communities had higher functional dissimilarity and functional evenness driven by differences in the modalities within body form, body size, larval development, and reproductive strategy. These traits primarily affect nutrient cycling, energy turnover, and recovery from disturbances, suggesting a stronger potential for future maintenance of ecosystem function, and indicating a more even use of resources in the Beaufort Sea. The combination of functional and taxonomic diversity metrics enabled a comprehensive understanding of how ecological niche space is used and how epibenthic communities function in Alaskan Arctic shelf systems.

*Corresponding author: 1sutton7@alaska.edu

$\S_{\text {Corrections were made after publication. Fig. } 5 \text { was re-drawn }}$ for better clarity. The data did not change.

This corrected version: October 6, 2020

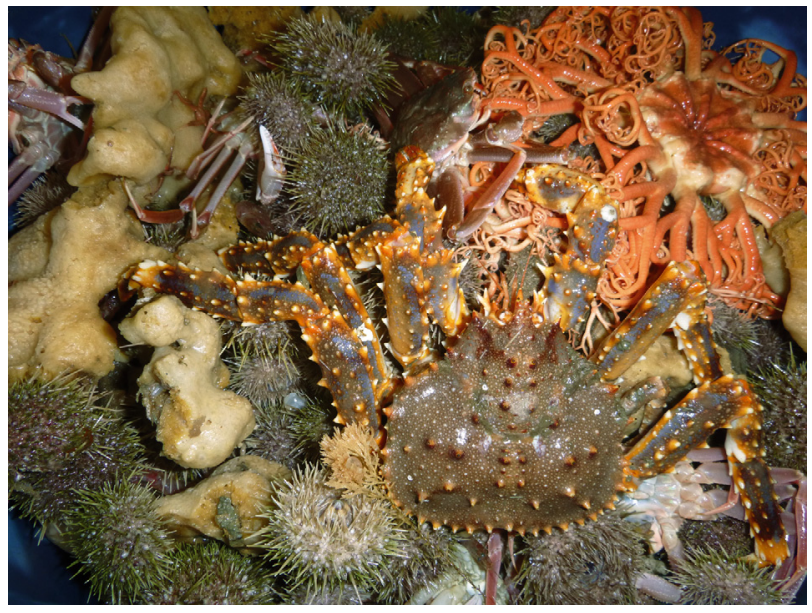

Differences in functional diversity and functional composition of epibenthic invertebrate assemblages on Alaskan Arctic shelves lead to differences in ecosystem functioning.

Photo: Katrin Iken

KEY WORDS: Biological traits . Biodiversityecosystem-functioning (BEF) · Niche space. Resource use · Invertebrates

\section{INTRODUCTION}

Arctic ecosystems are changing rapidly as the Arctic is warming twice as fast as the rest of the planet (Stroeve et al. 2012), with continued decreases in sea ice extent (Carmack et al. 2016) and changes in primary production (Arrigo \& van Dijken 2015, Frey et al. 2019). Ongoing shifts in the Arctic environment are associated with changes in marine community

(C) The authors 2020. Open Access under Creative Commons by Attribution Licence. Use, distribution and reproduction are unrestricted. Authors and original publication must be credited. 
composition and ecosystem processes (Huntington et al. 2020, Waga et al. 2020). For example, environmental changes, such as changes in temperature or sea ice, can increase stress for Arctic species but create habitat conditions suitable for northwardmoving boreal species, thus changing community composition (Mueter \& Litzow 2008, Thorson et al. 2019). Alaskan Arctic shelves are known for regionally high productivity and tight pelagic-benthic coupling, leading to some of the most productive benthic shelf areas in the world (Grebmeier et al. 2006). Arctic benthic assemblages within the Beaufort and Chukchi Sea shelf communities are of great importance for these ecosystem processes, as they support important food webs, which can channel anthropogenic or climatic perturbations to upper trophic levels (Iken et al. 2010, Divine et al. 2015). These benthivorous upper trophic levels include ecologically and socially important bearded seals, walruses (Fay 1982, Oliver et al. 1983), demersal fishes (Whitehouse et al. 2017), crabs (Divine et al. 2017), and birds (Lovvorn et al. 2003). Changes in benthic assemblages within shelf communities or in the energy pathways supporting these assemblages will therefore have effects on overall Arctic shelf ecosystem function.

Ecosystem function is broadly defined as the movement or storage of energy or material within an ecosystem (Bellwood et al. 2019). Benthic communities play important roles in ecosystem functions such as nutrient cycling (Kristensen 2000), energy turnover (Hall et al. 2009), trophic transfers (Iken et al. 2010), remineralization (Ambrose et al. 2001), and resuspension of sediments (Snelgrove et al. 2000). Although different Arctic benthic shelf communities may share these general functions, adjacent communities such as on the Beaufort and Chukchi Sea shelves - that differ distinctly in their oceanographic setting and primary production levels (Sakshaug 2004, Carmack \& Wassmann 2006) - can be expected to differ in the specific functional roles the benthos plays. The Chukchi Sea is a shallow inflow shelf (sensu Carmack \& Wassmann 2006), characterized by high nutrient influx from the Bering Sea, leading to high primary production. In contrast, the Beaufort Sea is a narrow interior shelf, which has lower primary production than the Chukchi Sea, driven by lower nutrient supplies from the Chukchi Sea to the western Beaufort shelf, upwelling from the shelf break, and high freshwater influx from the Mackenzie and Colville Rivers (Hill et al. 2013, 2018, Grebmeier \& Maslowski 2014). These differences in key environmental influences are suspected to play a role in driv- ing patterns in taxonomic composition (e.g. Rand et al. 2018) and may also lead to differences in functional composition through differences in biological traits between the Beaufort and Chukchi Sea shelf benthic communities. This could result in different ecosystem functioning between the 2 shelves, despite their proximity. Consequently, the responses and resilience (i.e. the ability of communities to maintain ecosystem function) of the benthic communities to perturbations will likely differ between the Beaufort and Chukchi Sea shelves.

Functional diversity within a geographical area can help explain and predict regional ecosystem functioning and ecosystem resilience to environmental change. The Beaufort and Chukchi Sea epibenthic communities can be functionally described by 'what they do' based on specific functional traits of the taxa within the community rather than 'who they are' purely based on taxonomy (Petchey \& Gaston 2006). Hence, functional diversity is defined as the range of organismal traits of species within a community that, combined, determines ecosystem functioning (Tilman 2001, Bremner et al. 2006). Different taxa can play a similar functional role in a community based on their traits. Conversely, taxonomically similar organisms can have different functions within a community (Hewitt et al. 2008, Krumhansl et al. 2016). Differences in biological trait expression within a community will lead to differences in resource use because biological traits represent how taxa extract and move resources in their environment (McGill et al. 2006, Cadotte et al. 2011). In essence, functional diversity is the balance of the roles of taxa within communities through different traits and through redundancy or complementarity of shared traits that influence overall ecosystem functioning (Díaz \& Cabido 2001).

Arctic marine communities are at particular risk of experiencing competitive disadvantages relative to invading boreal species. Although Arctic taxa typically occupy a narrow temperature range, modeling studies suggest these taxa may be resilient to environmental pressures, including high temperatures (Renaud et al. 2015, 2019). Therefore, there is a need to better understand the resilience of these Arctic shelf communities to ongoing changes in the environment. In a resilient system, a specific ecosystem function would be maintained even if one or several taxa were removed from the system. High functional redundancy, where the same biological traits are represented by several different species within a community, and high functional diversity, where many different traits are represented by taxa within 
a community, presumably lead to high ecosystem stability and increased resilience to change or disturbance (Hewitt et al. 2008).

The biodiversity-ecosystem-functioning (BEF) hypothesis states that higher taxonomic diversity leads to improved ecosystem functioning through diversified resource use, which ultimately leads to higher ecosystem stability (Loreau et al. 2001, Cardinale et al. 2009, 2012). This theory is based in an understanding of biodiversity from a taxonomic perspective, which for epibenthos has been established in recent years for the Beaufort and Chukchi Sea shelf study areas (e.g. Bluhm et al. 2009, Blanchard et al. 2013, Ravelo et al. 2014, 2015, 2020). The underlying assumption of the BEF hypothesis is that higher taxonomic diversity also reflects higher functional diversity, but these assumptions are rarely explicitly tested. Support for this underlying assumption, for example, has been found for the macrobenthos in the Bering Sea (Liu et al. 2019). Despite a long-standing and ongoing debate in the marine ecology scientific community of this concept (Naeem et al. 1994), few studies have analyzed the relationship between taxonomic diversity and ecosystem function in Arctic benthic marine systems (but see Kokarev et al. 2017, Rand et al. 2018, Liu et al. 2019), systems that are prone to perturbations. We contend here that, if the BEF assumption is correct, functional diversity on the 2 Arctic shelf communities should follow the same patterns as taxonomic diversity, as functional diversity is based in biological traits that are defined by a species' identity. However, if functional diversity provides a complementary perspective to ecosystem functioning that taxonomy alone does not provide, then a more comprehensive understanding of ecosystem function can be expected when functional diversity is analyzed alongside taxonomic diversity. Therefore, given distinct environmental influences on the 2 shelves, we hypothesized that (1) differences in functional composition and diversity metrics in epibenthic shelf communities reflect patterns in taxonomic composition and diversity metrics; and (2) patterns in functional diversity metrics of Beaufort and Chukchi Sea epibenthic shelf communities are distinct from each other.

\section{MATERIALS AND METHODS}

\subsection{Study sites}

Epibenthic invertebrates were collected during 4 cruises in 2014 and 2015 on the US Beaufort and Chukchi Sea shelves (Fig. 1). Here, we define each station as a representative assemblage of taxa within each shelf community. Beaufort Sea assemblages from 46 stations were studied during 3 research cruises: The US-Canada Transboundary Project 2014 sampled the central Beaufort Sea shelf, and the Arctic Nearshore Impact Monitoring in Development Area project III (ANIMIDA 2014, 2015) sampled the central and eastern Beaufort Sea shelf. Stations between 9 and $64 \mathrm{~m}$ bottom depth were included in this study. Chukchi Sea shelf assemblages from 67 stations were sampled during the Arctic Marine Biodiversity Observing Network survey in 2015 (AMBON 2015). These stations were sampled between 11 and $54 \mathrm{~m}$ bottom depth.

\subsection{Sample collection}

Epibenthic invertebrate assemblages were sampled during all cruises towing a $3.05 \mathrm{~m}$ wide plumbstaff beam trawl with a $2.6 \mathrm{~m}$ wide and $1.2 \mathrm{~m}$ high mouth opening with a $7 \mathrm{~mm}$ mesh and a $4 \mathrm{~mm}$ codend liner (modified after Gunderson \& Ellis 1986).

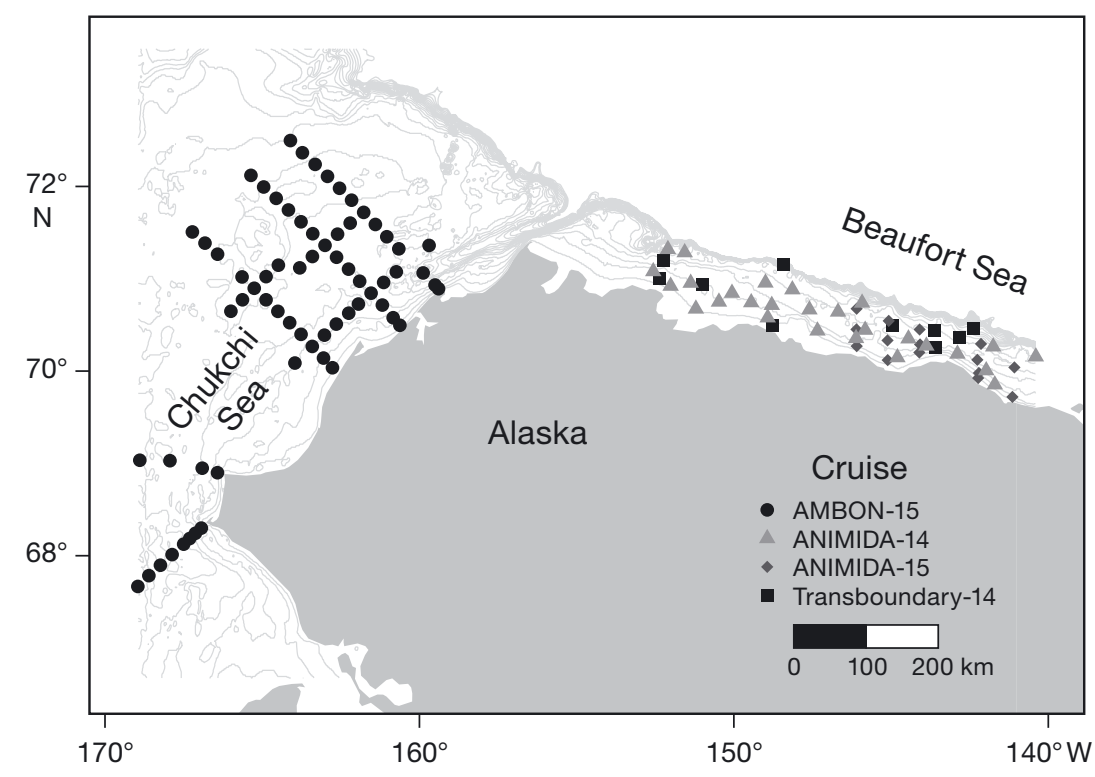

Fig. 1. Stations sampled for epibenthic communities during 4 cruises in the Beaufort and Chukchi Seas in 2014 and 2015. Stations are designated by symbols to different cruises. Depth contours in the study regions are shown in gray at $10 \mathrm{~m}$ intervals 
Average trawl time at the bottom was 4-5 min at approximately $1.5-2$ knots, depending on station depth and bottom conditions (see details in Iken et al. 2019). Biomass of all epibenthic invertebrates at each station was calculated as catch per unit effort by multiplying the estimated distance trawled by the width of the net and normalized to $g$ wet weight per $1000 \mathrm{~m}^{2}$. Bottom contact was determined using a time-depth recorder (Star Oddi). Invertebrates were identified onboard to the lowest feasible taxonomic level, and net wet weight of each taxon was recorded using digital hanging scales. Vouchers for taxa not identified in the field were fixed in either $10 \%$ formalin solution or 190-proof ethanol for later identification with the help of taxonomic experts listed in the acknowledgment section. Taxon names followed those in WoRMS (www.marinespecies.org) to standardize nomenclature.

\subsection{Biological traits analysis}

A dataset of biological traits was compiled for a total of 327 epibenthic taxa collected from both shelves. These data can be accessed via Table S1 in the Supplement (at www.int-res.com/articles/suppl/ m651p001_supp.xlsx) and with references via The Arctic Traits Database (https://www.univie.ac.at/ arctictraits/). The Beaufort Sea community consisted of 246 taxa and the Chukchi Sea community consisted of 247 taxa, with 166 shared taxa within these shelves. Taxonomic resolution varied for these taxa, but was similar between the 2 shelf communities. The Beaufort Sea had 163 and Chukchi Sea had 172 taxa identified to species, 60 and 56 to genus, 7 and 5 to family, 4 and 5 to class, 7 and 4 to order, and the same 5 taxa were identified at the phylum level (Table S1). Taxonomic identifications were based on the same taxonomic expertise (see Acknowledgements), so that the similar taxonomic resolution of the 2 sea shelf systems enabled an unbiased comparison of functional diversity based on biological traits. Biological traits analysis (BTA) functionally characterizes epibenthic organisms based on morphology, life history, and behavior. The BTA included a total of 9 traits related to morphology (body form, body size, fragility, sociability), behavior (feeding habit, living habit, adult movement), and life history (larval development, reproductive strategy), following the definitions and categories used by Degen \& Faulwetter (2019) (Table 1). The biological traits matrix was assembled through a combination of qualitative traits based on observations and our collective knowledge of Arctic invertebrates (morphological traits) and traits derived from extensive literature research (life history traits, behavioral traits). Where specific literature for a species was unavailable, traits were inferred from closely related species. Each trait was further separated into modalities to account for distinct categories within a trait that an organism could express (Table 1, Table S1).

The BTA was done with a fuzzy-coding approach, which allowed taxa to be assigned multiple modalities within a trait based on their affinity to those modalities (Chevenet et al. 1994, Bremner et al. 2006). Using a 0-3 scoring system, where 0 means no affinity and 3 is a high affinity to a modality, each taxon was assigned a number based on its affinity to each modality within a trait (Table S1, Chevenet et al. 1994). Taxa with equal affinity to several modalities within a biological trait were assigned the same score for those modalities. All fuzzy-coded modality scores within a trait were then weighted so that they summed to 1 for each taxon and trait. The scores for all modalities across all traits created unique taxa biological trait profiles (taxa by trait matrix). These matrices were multiplied by the relative taxa biomass at each station (taxa by station matrix) to create fuzzy-coded community weighted means (CWMs) for each station and trait. Therefore, the resulting station by trait matrix essentially highlighted the most common categorical modalities at each station, and therefore each assemblage, through biomass weighting (Table 2) (Garnier et al. 2007).

\subsection{Shelf comparisons of functional and taxonomic diversity metrics}

Five functional diversity metrics were calculated for the Beaufort and Chukchi Sea shelf epibenthic assemblages to enable a community-level comparison (Table 2). Each of the functional diversity metrics represented a unique facet of overall functional diversity (Mason et al. 2005, Mouchet et al. 2010). These included functional dissimilarity (Rao's quadratic entropy [Rao's Q]), functional richness (FRic), functional evenness (FEve), functional divergence (FDiv), and functional redundancy (FRed = 1 - mean pairwise distances [MPD]) (Table 2). Functional dissimilarity (Rao's Q) compares how similar the biological trait profiles of taxa are to each other among assemblages (Rao 1982). Functional dissimilarity was complemented by functional metrics that described 


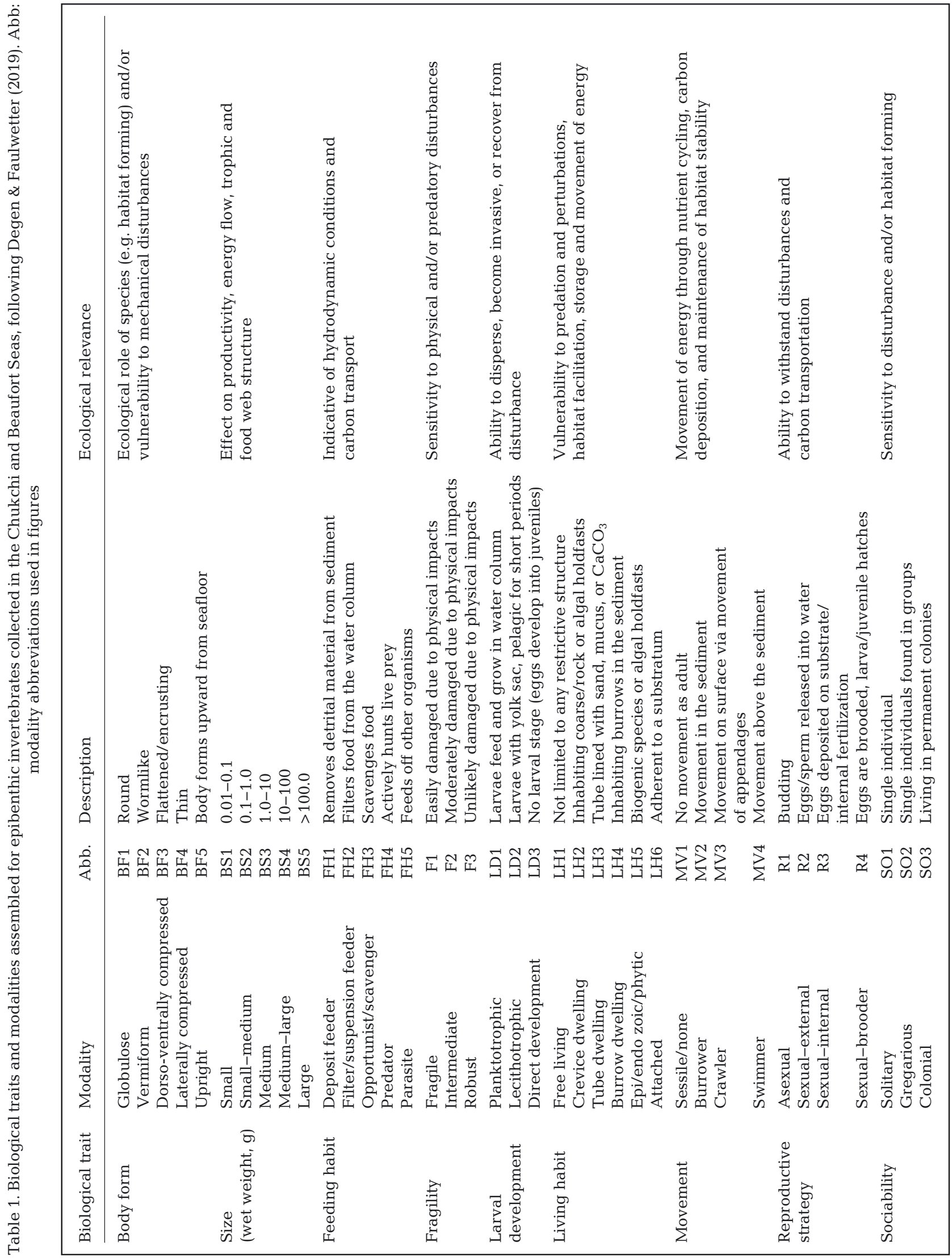




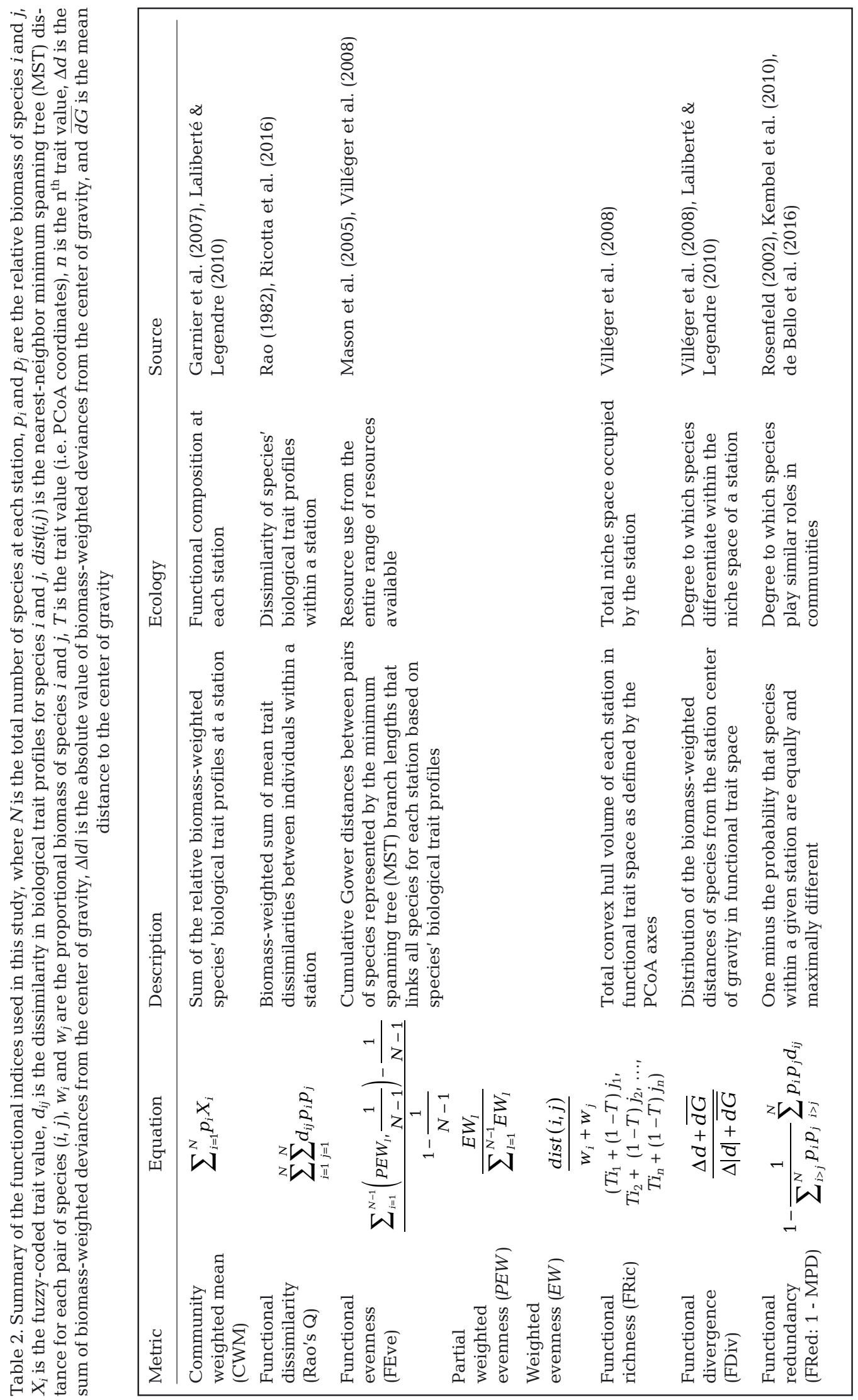


the available functional niche space (FRic) and how the space within a given niche was occupied among assemblages (FEve, FDiv) (Schleuter et al. 2010). As all traits were fuzzy-coded categorical variables, functional metrics of Rao's Q, FRic, FEve, and FDiv were based on a flexible distance-based framework (Laliberté \& Legendre 2010). First, a Gower distance matrix among taxa was calculated using a trait by taxa matrix, followed by a principal coordinates analysis (PCoA). PCoA axes were then used as new 'trait values' to compute FRic, FEve, and FDiv for all stations (Laliberté \& Legendre 2010). FEve used all PCoA axes, whereas FRic and FDiv used the maximum number of PCoA axes allowed where the number of taxa was greater than the number of traits. FRed represents the degree to which taxa play similar roles in communities, and was measured using the complement of MPD (1 - MPD) (Rosenfeld 2002, de Bello et al. 2016). All functional diversity metrics can range from 0-1, where 0 indicates low functional diversity and 1 indicates the highest possible functional diversity.

Functional diversity metrics were compared to complementary taxonomic diversity metrics (Table 3). Rao's Q was compared to the Simpson taxonomicbased diversity index (Simpson 1949). Simpson diversity measures the chance that 2 individuals within a station are from the same taxon. The Simpson diversity index equals the maximum value of Rao's $Q$ if all taxa were functionally completely different (i.e. each taxon represents unique functions) and the Simpson index is, thus, commonly used in compar- isons of functional and taxonomic diversity (Carmona et al. 2016). Margalef's richness index measures species richness while accounting for sampling effects, and was compared to FRic. Finally, Pielou's evenness index was used to calculate species evenness and was compared to FEve.

All diversity metrics were compared between the Beaufort and Chukchi Sea shelf communities using a linear model of the form:

$$
y=\alpha+\beta \times d+\varepsilon
$$

where $y$ is any of the diversity metrics, the intercept $\alpha$ corresponds to the mean value of index $y$ for the Chukchi Sea, and $d$ is a dummy variable with values $d=0$ for the Chukchi Sea and $d=1$ for the Beaufort Sea. Hence, the regression coefficient $\beta$ corresponds to the mean difference in metric $y$ between the Chukchi Sea and the Beaufort Sea. The error, $\varepsilon$, was modeled as a spatial random process with a correlation structure that exponentially declined with distance between stations to allow for spatial autocorrelation. This linear model form was chosen over a simple univariate test (e.g. ANOVA) due to the spatial nature of the residuals and the ability to account for spatial autocorrelation. Models were fit using a generalized-least-squares approach as implemented in the 'nmle' package in R (Pinheiro et al. 2017). If the autocorrelation term did not significantly improve the model fit, metrics were compared using a simple linear model fit via least squares. To further investigate the relationship between the number of taxa and functional diversity on each shelf, Rao's Q was com-

Table 3. Summary of the taxonomic-based metrics used in this study, where $S_{i}$ is the biomass of species $i, S$ is the total biomass of all species at each station, $N$ is the total number of species at each station, and $p_{i}$ is the relative biomass of species $i$ at a station

\begin{tabular}{|c|c|c|c|}
\hline Index & Formula & Description & Source \\
\hline Simpson diversity index $(D)$ & $1-\sum_{i=1}^{N} \frac{S_{i}\left(S_{i}-1\right)}{S\left(S_{i}-1\right)}$ & $\begin{array}{l}\text { Equals the maximum value for } \\
\text { Rao's Q if all species were } \\
\text { completely functionally } \\
\text { different (i.e. each species } \\
\text { represents unique functions) }\end{array}$ & Simpson (1949) \\
\hline Margalef's richness index $(d)$ & $\frac{S-1}{\ln (N)}$ & $\begin{array}{l}\text { Result of the number of } \\
\text { species divided by the } \\
\text { biomass of species at a given } \\
\text { station }\end{array}$ & Magurran (2004) \\
\hline Pielou's evenness index $\left(J^{\prime}\right)$ & $\frac{H^{\prime}}{\log (S)}$ & $\begin{array}{l}\text { Maximum possible value of } \\
\text { the Shannon index }\left(H^{\prime}\right)\end{array}$ & Pielou (1975), Magurran (2004) \\
\hline Shannon diversity index $\left(H^{\prime}\right)$ & $-\sum_{i=1}^{S} p_{i} \ln \left(p_{i}\right)$ & $\begin{array}{l}\text { Proportion of species even- } \\
\text { ness relative to species } \\
\text { biomass at a station }\end{array}$ & Shannon (1948) \\
\hline
\end{tabular}


pared to Margalef's index for the Beaufort and Chukchi Sea shelves using a non-linear generalized additive model (GAM).

\subsection{Comparisons of functional and taxonomic composition}

Significant differences in functional (based on CWM) and taxonomic composition (based on taxon biomass) between the Beaufort and Chukchi Sea shelf assemblages were determined with analyses of similarity (ANOSIM) using a Gower distance matrix for functional composition and a Bray-Curtis dissimilarity matrix for taxonomic composition (Clarke \& Warwick 1994). No transformation was performed on the functional composition matrix, as this matrix was already fuzzy-coded for CWM. Taxon biomass data were square root transformed to balance the influence of rare and dominant taxa (Clarke \& Warwick 1994). The 10 most influential taxa on taxonomic composition were compared between the 2 shelves (similarity percentages analysis, SIMPER). These taxa were further compared between shelves in percent total biomass, frequency of occurrence, and average percent biomass per station. Furthermore, functional composition based on the proportion of modalities within biological traits was compared between the Beaufort and Chukchi Sea shelf communities using a fuzzy correspondence analysis

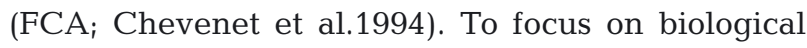
traits that drove patterns in functional composition on each shelf, correlation ratios from the FCA were evaluated for the first 2 axes of the FCA. High correlation ratios indicate strong relationships of biological traits with the FCA axes. Following previous studies on biological traits (Conti et al. 2014, Kokarev et al. 2017), we considered biological traits with correlation ratios $>0.1$ as most representative of the variance captured by the FCA axes. All analyses evaluating differences in functional and taxonomic compositions were computed using the 'vegan' package (Oksanen et al. 2019) in $\mathrm{R}$ version 4.0.2 (R Core Team 2020). Functional and taxonomic composition for each shelf were compared using the RELATE routine in the Primer V.7 software package (Clarke \& Gorley 2015). Sufficient permutations were possible for all comparisons, and statistical significance was set at $\alpha=0.05$.

In addition to between-shelf comparisons, the relationships of functional and taxonomic structures were evaluated within each shelf using a multistep process of multivariate statistics. First, we investi- gated which taxa and modalities best represented communities for each shelf using the BVSTEP analysis within the BEST routine in Primer V.7 (Clarke \& Gorley 2015). Specifically, we investigated which subset of taxa or subset of modalities were necessary to maintain the original structures of taxonomic or functional composition and were therefore considered representative of the functional and taxonomic structure. These representative subsets of modalities and taxa were determined using a stepwise procedure based on at least $95 \%$ Mantel correlations. Subsequently, these subsets were considered as characteristic taxa and influential modalities. Resemblance matrices from these characteristic species and influential modalities were then compared using RELATE tests for each shelf separately.

\section{RESULTS}

\subsection{Functional and taxonomic diversity metrics}

All diversity metrics except FRed had higher median values in the Beaufort Sea shelf community compared to the Chukchi Sea shelf community. However, only 2 functional diversity metrics (Rao's $\mathrm{Q}, \mathrm{FEve}$ ) and the corresponding taxonomic metrics (Simpson's diversity, Pielou's evenness) were significantly higher in the Beaufort than Chukchi Sea shelf community (Fig. 2, p < 0.01). No spatial autocorrelation was detected for Rao's Q, FRic, Simpson diversity, and Pielou's evenness, but was present in FEve, FDiv, Margalef's index, and FRed (Table 4). Fewer taxa were required to increase functional dissimilarity (Rao's Q) in the Beaufort Sea compared to the Chukchi Sea (Fig. 3).

\subsection{Comparison in functional and taxonomic composition between shelves}

The Beaufort and Chukchi Sea epibenthic shelf communities moderately differed in functional composition, despite substantial overlap (ANOSIM: R = $0.292, \mathrm{p}=0.001$, Fig. 4a). The first 2 FCA axes accounted for $42.36 \%$ of the total inertia, with $24.70 \%$ explained by axis 1 and $17.66 \%$ explained by axis 2 (Fig. 4a). The biological trait movement was mostly separated along axis 1, while fragility was mostly separated along axis 2 (Fig. 5). The biological traits body form, body size, larval development, and reproductive strategy were strongly correlated with both axes, with correlation ratios $\geq 0.1$ (Table 5, Fig. 5). 

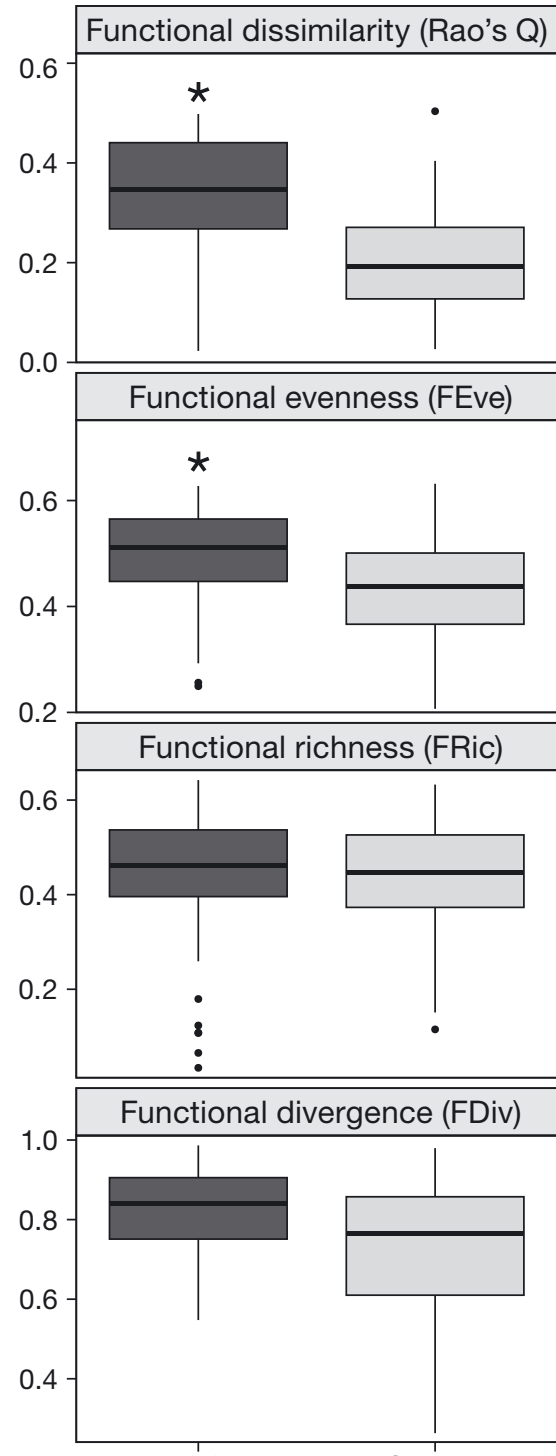

Beaufort

Chukchi
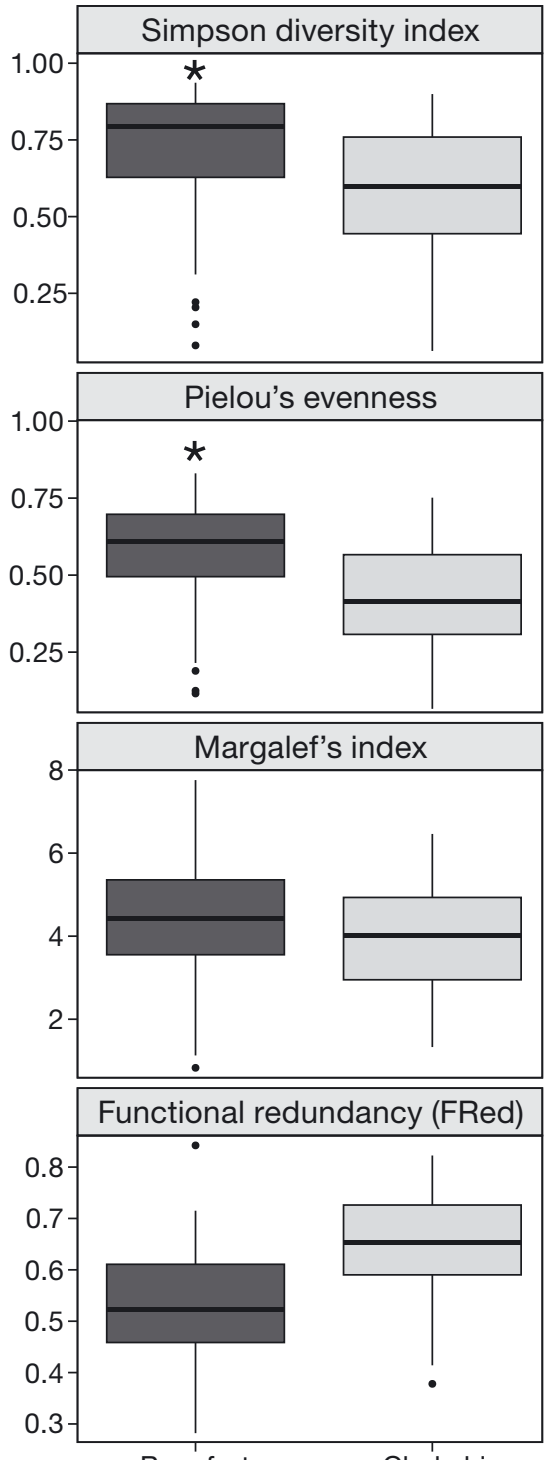

Beaufort masses of dorso-ventrally compressed (BF3) and upright (BF5) body form, planktotrophic development (LD1), medium (BS3) and medium-large size (BS4), and sexual-external (R2) modalities (Fig. 6).

The Beaufort and Chukchi Sea epibenthic shelf communities also differed in taxonomic composition (ANO SIM, R = 0.676, $p=0.001$, Fig. 4b). The Beaufort Sea shelf contained 246 taxa and the Chukchi Sea shelf harbored 247 taxa, with a total of 327 unique taxa combined for the 2 shelves. Of the total taxa, 166 taxa (51\% of total) were shared between the Beaufort and Chukchi Sea shelf communities. The holothurian Psolus peronii, the scallop Similipecten greenlandicus, the brittle stars Ophiocten sericeum and Ophiura sarsii, the snow crab Chionoecetes opilio, the sand dollar Echinarachnius parma, the shrimp Argis sp., the basket star Gorgonocephalus sp., and the lyre crab Hyas coarctatus contributed most to differences in taxonomic composition between the 2 shelves (SIMPER, Table 6, Fig. 4b). The 2 shelf communities differed strongly in the taxa that contributed most to biomass and frequency of occurrence (FO) per shelf. The Beaufort Sea shelf community was dominated in total biomass, average biomass per station, and FO by $P$. peronii, S. greenlandicus, and $O$. sericeum. In contrast, the Chukchi Sea shelf community was dominated in total biomass and average biomass per station by $O$. sarsii, $C$. opilio, and $E$. parma, while $\mathrm{FO}$ was highest for $C$. opilio, Argis sp., and H. coarctatus (Table 6). (see Table 4)

Within these biological traits that strongly correlated with both FCA axes, the Beaufort Sea shelf assemblages had proportionally higher biomasses of globulose (BF1) and laterally compressed (BF4) body forms, lecithotrophic (LD2) and direct development (LD3), small-medium sized (BS2), and sexualbrooder (R4) modalities compared with Chukchi Sea assemblages (Fig. 6). Conversely, the Chukchi Sea shelf assemblages had proportionally higher bio-

\subsection{Comparison of functional and taxonomic composition within each shelf}

Patterns in functional and taxonomic composition were significantly related to each other within both the Beaufort and Chukchi Sea shelf communities (RELATE test: rho $=0.497, \mathrm{p}=0.001$ for Beaufort Sea; rho $=0.619, \mathrm{p}=0.001$ for Chukchi Sea). Eight taxa best characterized the Beaufort Sea shelf taxonomic 
Table 4. Metrics compared between the Beaufort and Chukchi Seas, model structure (with or without spatially autocorrelated residuals), estimated mean for the Beaufort Sea (intercept $\alpha$ ), difference between Chukchi and Beaufort Sea means $(\beta)$, and significance level for $\beta$. Significant differences $(p \leq 0.05)$ in bold. Rao's Q: Rao's quadratic entropy (a measure of functional dissimilarity); FEve: functional evenness; FRic: functional richness; FDiv: functional divergence; FRed: functional redundancy; other indices are defined in Table 3

\begin{tabular}{|lcccc|}
\hline Metric & $\begin{array}{c}\text { Spatial auto- } \\
\text { correlation }\end{array}$ & $\alpha(\mathrm{CI})$ & $\beta$ & $\begin{array}{c}\text { Significance } \\
\left(H_{0}: \beta=0\right)\end{array}$ \\
\hline Rao's Q & No & $0.326(0.294-0.358)$ & $\mathbf{- 0 . 1 2 6}$ & $\mathbf{< 0 . 0 0 1}$ \\
Simpson & No & $0.707(0.644-0.771)$ & $\mathbf{- 0 . 1 3 6}$ & $\mathbf{0 . 0 0 2}$ \\
FEve & Yes & $0.493(0.449-0.053)$ & $\mathbf{- 0 . 0 5 6}$ & $\mathbf{0 . 0 5 3}$ \\
Pielou & Yes & $0.588(0.503-0.672)$ & $\mathbf{- 0 . 1 3 7}$ & $\mathbf{0 . 0 2 0}$ \\
FRic & No & $0.431(0.392-0.470)$ & -0.003 & 0.827 \\
Margalef & Yes & $4.501(3.858-5.145)$ & -0.768 & 0.078 \\
FDiv & Yes & $0.793(0.651-0.936)$ & -0.123 & 0.464 \\
FRed & Yes & $0.553(0.461-0.644)$ & 0.228 & 0.276 \\
\hline
\end{tabular}

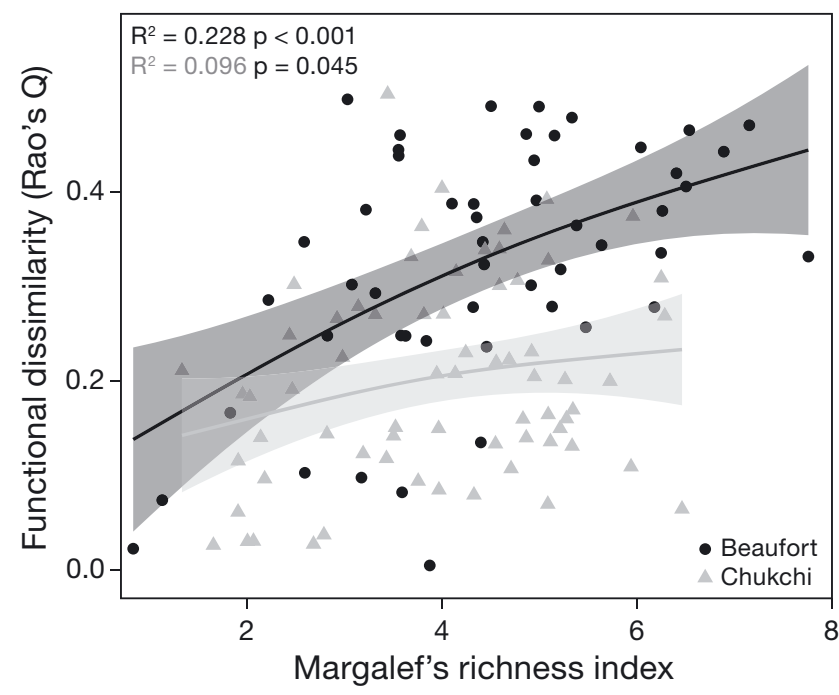

Fig. 3. Functional dissimilarity (Rao's Q) in the Beaufort Sea (dark gray) and Chukchi Sea (light gray) as a function of species richness (Margalef's index). Trends and confidence intervals estimated based on a generalized additive model (GAM) smoother to visualize the general trends

structure (BVSTEP, Spearman's correlation coefficient: $0.952, p=0.001$, Fig. $7 a$ ). These taxa were the amphipods Acanthostepheia behringiensis and Paroediceros lynceus, the cumacean Diastylis goodsiri, the seastars Leptasterias groenlandica and Urasterias lincki, the brittle star $O$. sericeum, the holothurian P. peronii, and the shrimp Sabinea septemcarinata. Six modalities contributed most to the Beaufort Sea functional structure (BVSTEP, Spearman's correlation coefficient: 0.951, $\mathrm{p}=0.001$ ). These modalities were dorso-ventrally compressed (BF3), robust (F3), sessile (MV1), sexual-brooding
(R4), sexual-external reproduction (R2), and solitary (SO1). These influential modalities were well represented by the characteristic taxa (Fig. 7a). In this matrix of characteristic taxa by modality, $48 \%$ of the possible taxamodality pairings reflected some affinity to each other, often even high affinity. Resemblance matrices of the subset of characteristic taxa and the influential modalities for the Beaufort Sea were significantly related (RELATE; rho $=0.569, \mathrm{p}=0.01$ ).

A larger subset of taxa and modalities were needed in the Chukchi than the Beaufort Sea community to maintain taxonomic and functional structure. We found that 28 taxa best characterized Chukchi Sea shelf taxonomic structure across all stations (BVSTEP, Spearman's correlation coefficient: 0.951, $p=0.01$; Fig. 7b). Eleven modalities that most influenced the Chukchi Sea functional structure (BVSTEP, Spearman's correlation coefficient: $0.905, \mathrm{p}=0.001$ ) were direct development (LD1), lecithotrophic development (LD2), fragile (F1), gregarious (SO2), solitary (SO1), laterally compressed (BF4), upright (BF5), medium size (BS3), predator (FH4), sessile (MV1), and swimmer (MV4). Influential modalities in the Chukchi Sea were expressed to a lesser degree $(39 \%)$ by the characteristic taxa, and often at a lower affinity than in the Beaufort Sea (Fig. 7b). Resemblance matrices of the subset of characteristic taxa and influential modalities for the Chukchi Sea were significantly related $($ RELATE; rho $=0.517, \mathrm{p}=0.01)$.

\section{DISCUSSION}

This study described the functional composition of the Beaufort and Chukchi Sea epibenthic shelf communities and explored the functional and taxonomic relationships between the 2 shelf systems. Overall, functional diversity patterns reflected those in taxonomic diversity on each shelf, supporting our first hypothesis. In addition, we found that the 2 shelves were functionally distinct, supporting our second hypothesis, albeit with much overlap in similar proportions of modalities between the 2 shelves. The biological traits that differed between shelves, especially those related to larval development, reproductive strategy, body size, and body form, can inform about energy flow and resource 

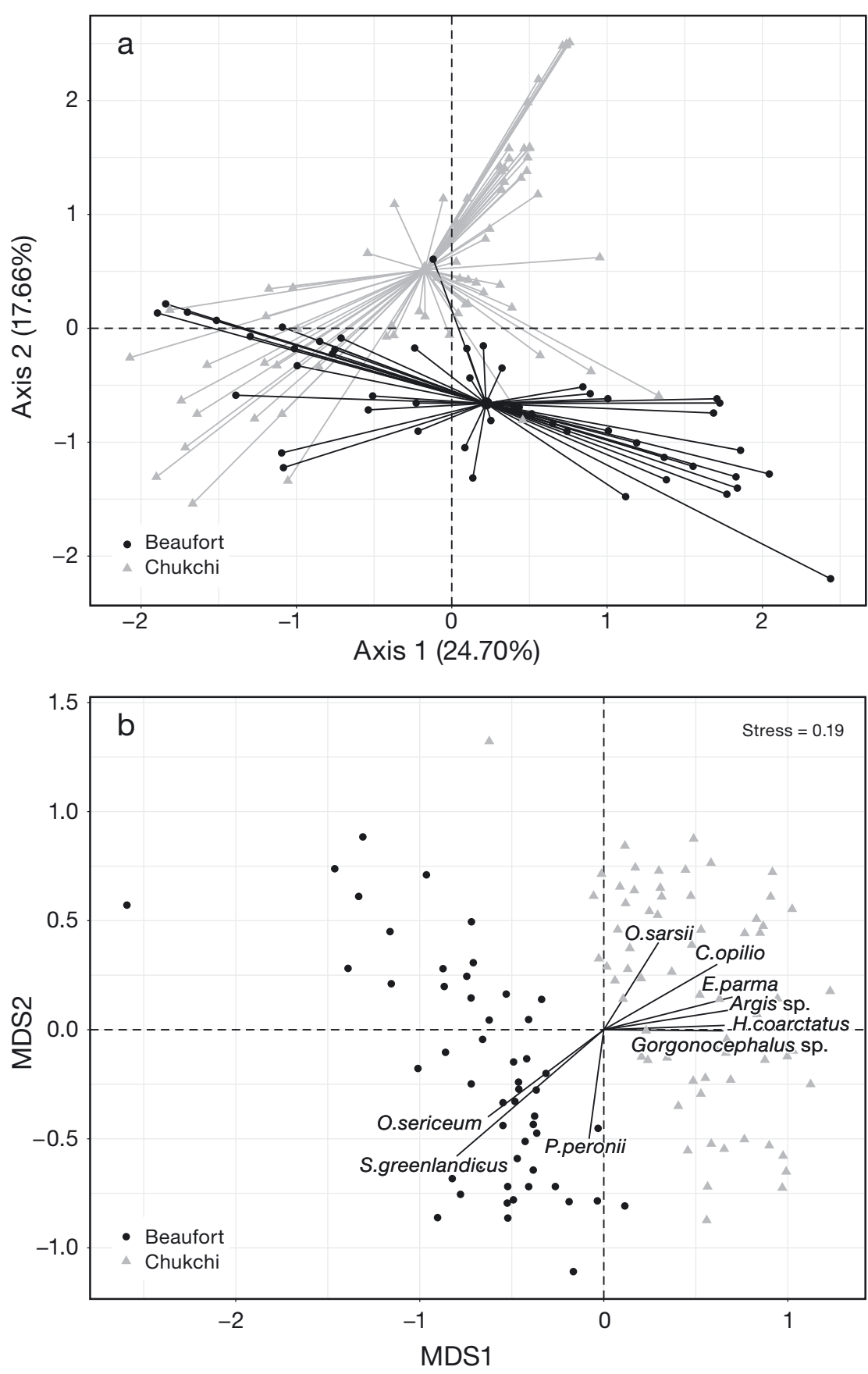

Fig. 4. (a) Fuzzy correspondence analysis (FCA) of functional composition and (b) non-metric multidimensional scaling (nMDS) plot of taxonomic composition of the Beaufort and Chukchi Sea shelf epibenthic communities. Each point represents a station in the Beaufort (dark gray) or Chukchi (light gray) Sea. Functional composition was based on the proportion of communityweighted-mean modalities expressed at each station, while taxonomic composition was based on square root transformed biomass. Vectors in the FCA (a) represent the distance of stations to the centroid for each shelf system. Vectors in the nMDS (b) represent taxa that contributed most to differences in taxonomic composition between the 2 shelves (SIMPER analysis). The direction of vectors in the nMDS indicates where taxon biomass increased and influenced the ordination, and vector length indicates the strength of the pattern in taxon biomass along that direction. Full species names are given in Table 5 partitioning within each shelf as well as different community responses to changes and disturbances (Rand et al. 2018). The overlap in functional composition, but strong separation of taxonomic composition between the Beaufort and Chukchi shelves, suggests that different taxa fulfill similar functions in the 2 systems. Therefore, functional analyses provided complementary perspectives that related the taxonomic patterns to ecosystem function on these Arctic shelves. Specifically, we can use dominant biological traits to pinpoint which resources (e.g. available food or space) are most affected by changes or perturbations in the available niche space, and how efficiently those niche spaces are occupied on these 2 shelf systems.

\subsection{Comparison of taxonomic and functional diversity metrics}

At the core of the BEF concept is the premise that higher taxonomic diversity leads to more efficient ecosystem functioning through higher interaction strength between taxa and their environment. The principle is that more species will use a more diverse set of resources in a system, ultimately increasing the stability of the system against perturbations (Loreau et al. 2001, Cardinale et al. 2009, 2012). In our study, taxonomic diversity (Simpson) and evenness (Pielou's) were significantly higher in the Beaufort Sea shelf assemblages compared to the Chukchi Sea shelf assemblages, but there was no difference in taxonomic richness (Margalef's index) between the 2 shelves. This similarity in taxonomic richness as well as in functional richness between the 2 shelf systems provided a unique opportunity to compare functional redundancy of the 2 shelves in similar taxonomic and functional space. Fewer modalities and fewer taxa were needed to describe the 

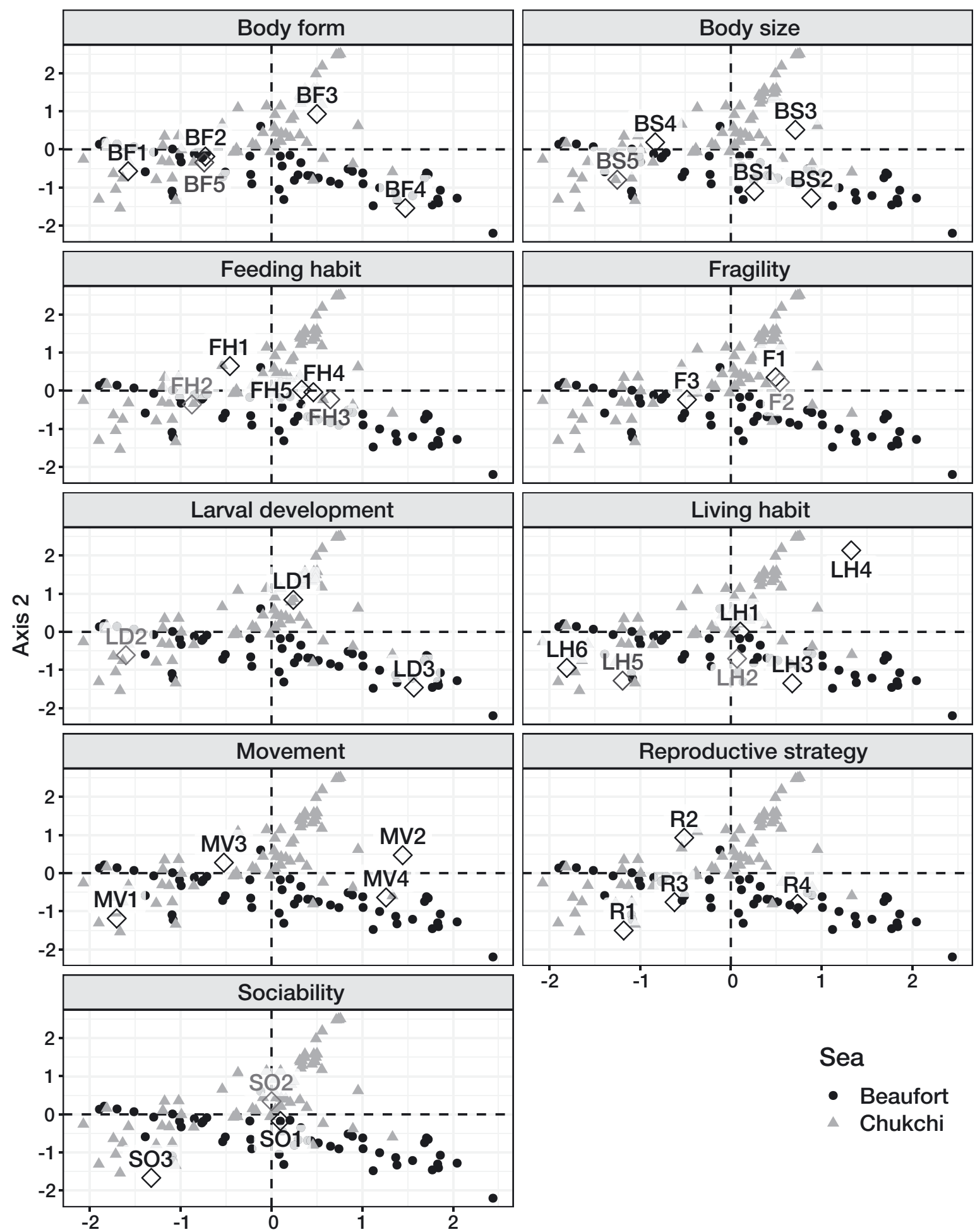

Sea

- Beaufort

$\triangle$ Chukchi

Fig. 5. Fuzzy correspondence analysis plots of functional composition for stations from the Beaufort (dark gray circles) and Chukchi Sea (light gray triangles) for all biological traits of epibenthic taxa. Modalities are denoted by diamonds with corresponding colors of abbreviated modality names. Position of the modalities is representative of association strength and influence on the ordination. For modality definitions and modality abbreviations see Table 1 
Table 5. Correlation ratios of the biological traits for the first 2 fuzzy correspondence analysis (FCA) axes (see Fig. 4a). Biological traits (trait details in Table 1) that accounted for the most variation in the FCA (correlation values $[R S] \geq 0.1$ ) are shown in bold

\begin{tabular}{|lrc|}
\hline Trait & RS1 & RS2 \\
\hline Body form & $\mathbf{0 . 2 6}$ & $\mathbf{0 . 2 1}$ \\
Body size & $\mathbf{0 . 1 7}$ & $\mathbf{0 . 1 1}$ \\
Fragility & 0.06 & $\mathbf{0 . 1 2}$ \\
Feeding habit & 0.09 & 0.03 \\
Larval development & $\mathbf{0 . 3 0}$ & $\mathbf{0 . 2 2}$ \\
Living habit & 0.08 & 0.07 \\
Movement & $\mathbf{0 . 2 6}$ & 0.07 \\
Reproductive strategy & $\mathbf{0 . 1 0}$ & $\mathbf{0 . 1 9}$ \\
Sociability & 0.02 & 0.04 \\
Variance (\%) & & \\
Eigenvalues & 24.70 & 17.66 \\
& 0.15 & 0.11 \\
\hline
\end{tabular}

relationships between taxonomic and functional composition of the Beaufort Sea community (8 taxa, 6 modalities) compared to the Chukchi Sea community (28 taxa, 11 modalities; see Fig. 7), reflecting a higher functional redundancy in the Chukchi Sea. Additionally, fewer taxa were required in the Beaufort Sea to increase functional dissimilarity compared to the Chukchi Sea at a given taxon richness. Together, these relationships point to lower functional redundancy and highly diverse biological trait profiles in the Beaufort Sea that tended to be dominated by single modalities within biological traits. High functional evenness in the Beaufort Sea indicated that most biological traits within assemblages were expressed evenly in functional space, albeit with individual taxa dominated by unique modalities. Likewise, the higher taxonomic evenness pointed to more evenly distributed biomass of taxa on the Beaufort Sea shelf. Our results show that, in general, functional diversity metrics measured on Alaskan Arctic shelf systems mirrored those of taxonomic metrics, following the hypothesized pattern of the BEF concept. Similar patterns between functional and taxonomic composition were found for the Bering Sea macrobenthos (Liu et al. 2019).

Given that species are the building blocks of ecosystem function (Bellwood et al. 2019), functional diversity can pinpoint which characteristics, or traits, of species diversity influence ecosystem function (Tilman 2001). For example, we saw strong differences between shelves in body size, likely affecting the movement of energy across the shelves,

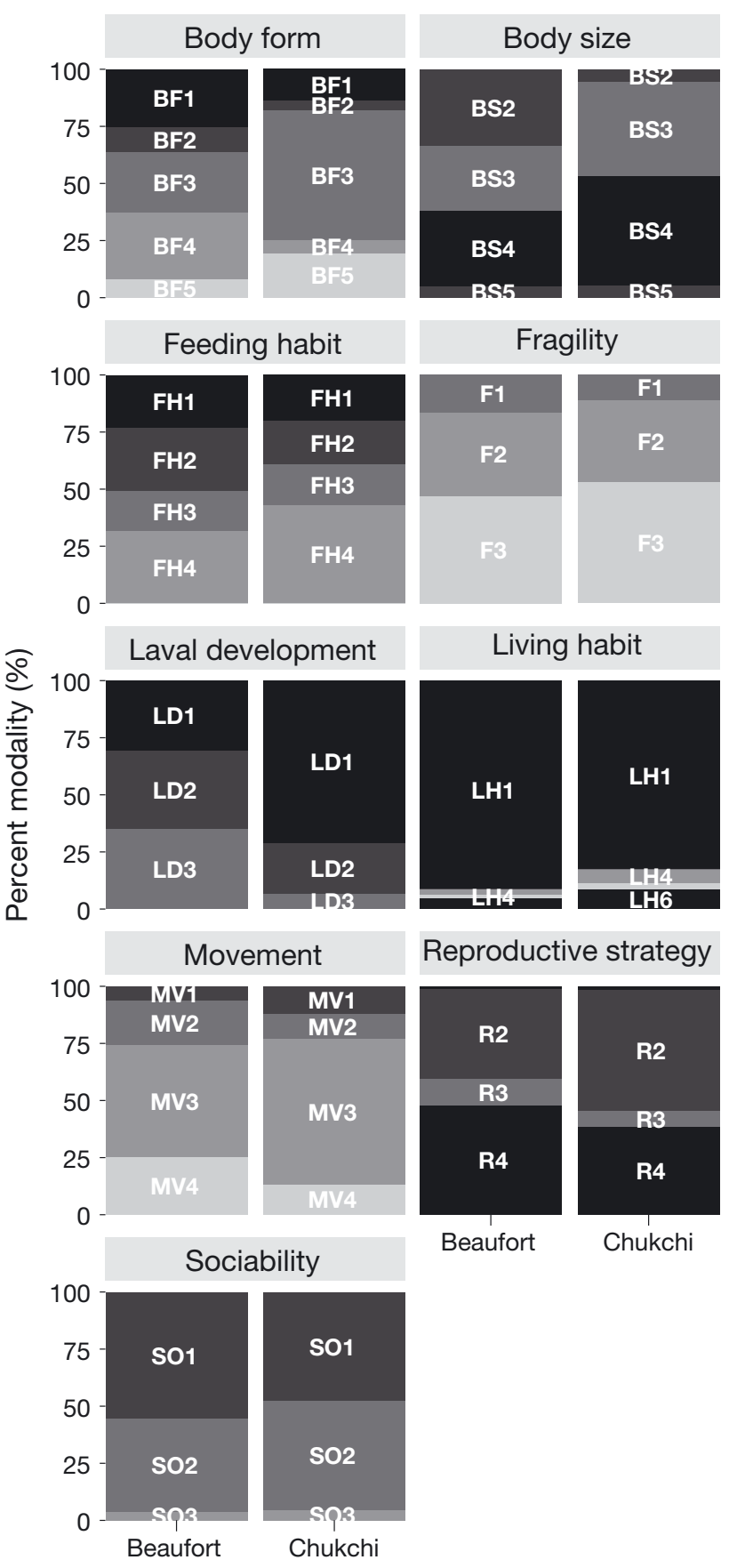

Fig. 6. Percent of each modality within each biological trait for the Beaufort (left bars) and Chukchi (right bars) Sea shelf epibenthic communities. Only modalities that contributed $>2 \%$ of the total sea community weighted mean (CWM) biomass are shown. Modality abbreviations as in Table 1

and in larval development, reproductive strategy, and body form, all of which can inform about resistance to disturbances. This relationship between the 2 diversity approaches emphasizes the importance of using functional diversity as a com- 
Table 6. Epibenthic taxa with the largest percent contribution to differences in taxonomic composition between the Beaufort (Beau) and Chukchi (Chuk) Sea shelves, ordered from highest to lowest contribution. The cumulative percent of total biomass for influential taxa is shown

\begin{tabular}{|c|c|c|c|c|c|c|c|c|}
\hline \multirow[t]{3}{*}{ Species } & \multicolumn{2}{|c|}{ SIMPER results (\%) } & \multicolumn{2}{|c|}{ Total biomass (\%) } & \multirow{2}{*}{\multicolumn{2}{|c|}{$\begin{array}{l}\text { Frequency of } \\
\text { occurrence }(\%)\end{array}$}} & \multirow{2}{*}{\multicolumn{2}{|c|}{$\begin{array}{c}\text { Average biomass per } \\
\text { station when present }(\%)\end{array}$}} \\
\hline & Indiv. & Cum. & Chuk & Beau & & & & \\
\hline & contrib. & contrib. & & & $\begin{array}{l}\text { Chuk } \\
\mathrm{n}=67\end{array}$ & $\begin{array}{c}\text { Beau } \\
\mathrm{n}=52\end{array}$ & $\begin{array}{c}\text { Chuk } \\
\mathrm{n}=67\end{array}$ & $\begin{array}{l}\text { Beau } \\
\mathrm{n}=52\end{array}$ \\
\hline Chionoecetes opilio & 6.9 & 6.9 & 7.0 & $<0.1$ & 94.0 & 7.7 & 1.4 & 0.1 \\
\hline Ophiura sarsii & 6.9 & 13.8 & 22.5 & 0.5 & 50.8 & 7.7 & 8.4 & 2.1 \\
\hline Psolus peronii & 5.2 & 19.0 & 6.0 & 41.1 & 26.9 & 51.9 & 4.3 & 24.7 \\
\hline Echinarachnius parma & 3.9 & 22.9 & 33.0 & 0 & 11.9 & 0 & 52.4 & 0 \\
\hline Ophiocten sericeum & 2.9 & 25.8 & $<0.1$ & 11.1 & 6.0 & 80.8 & 0.1 & 4.3 \\
\hline Similipecten greenlandicus & 2.5 & 28.3 & 0 & 7.3 & 0 & 78.9 & 0 & 2.9 \\
\hline Argis sp. & 2.2 & 30.6 & 0.9 & 0.1 & 82.1 & 7.7 & 0.2 & 0.2 \\
\hline Gorgonocephalus sp. & 2.2 & 32.8 & 2.8 & $<0.1$ & 43.3 & 1.9 & 1.2 & 0.4 \\
\hline Hyas coarctatus & 2.1 & 34.9 & 1.3 & 0.1 & 82.1 & 9.6 & 0.3 & 0.5 \\
\hline Number of taxa & & & 247 & 246 & & & & \\
\hline $\begin{array}{l}\text { Total average biomass } \\
\text { per station ( } \mathrm{g} \text { wet weight } \\
\text { per } 1000 \mathrm{~m}^{2} \text { ) }\end{array}$ & & & 3849 & 16910 & & & & \\
\hline Percent of total biomass & & & 73.42 & 60.20 & & & & \\
\hline
\end{tabular}

a

Acanthostepheia behringiensis

Diastylis goodsiri -

Leptasterias groenlandica

Ophiocten sericeum

Paroediceros lynceus

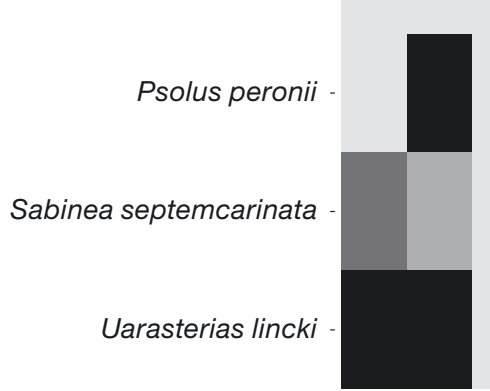

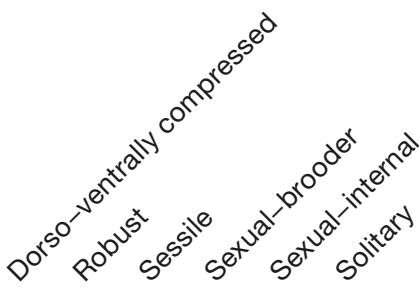

$\mathrm{b}$

Alcyonidium gelatinosum
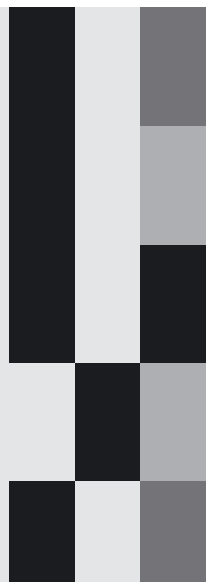
Lebbeus groenlandicus
Leptasterias groenlandica Leptasterias polaris Margarites costalis Myriotrochus rinkii Nemertea Neptunea heros Ophiura sarsii - Pagurus capillatus Pagurus trigonocheirus Psolus peronii Strongylocentrotus pallidus Styela rustica
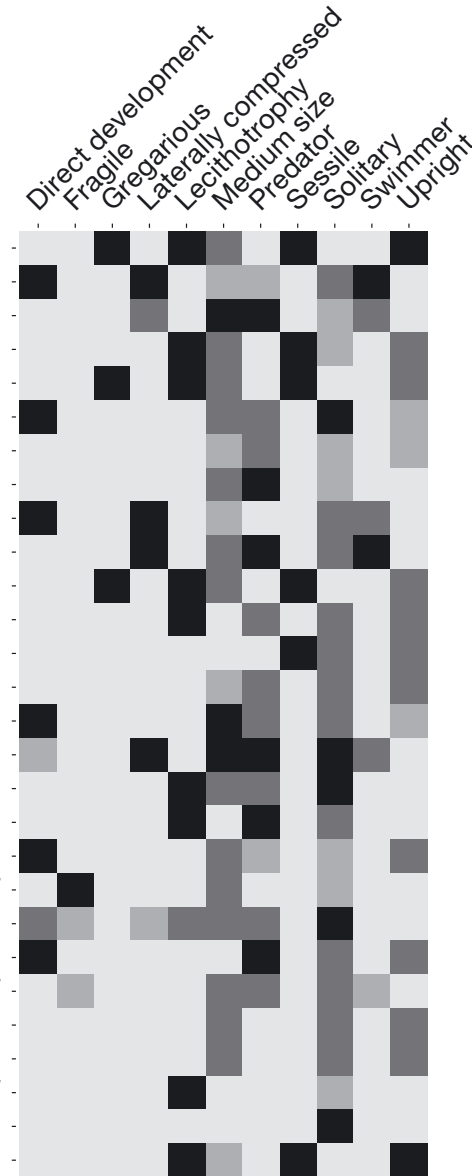

Fig. 7. Matrix of pairwise affinities between characteristic taxa and influential modalities in the (a) Beaufort Sea and (b) Chukchi Sea based on BVSTEP analyses with Spearman's correlation coefficient $>0.95$ and $p \leq 0.001$. Shading represents the affinity of a taxon for a given modality (from white = low affinity [0] to dark gray = high affinity [3]) 
plement to taxonomic diversity, especially on Arctic shelves (Rand et al. 2018), considering ecosystem function is likely to change with expected changes in taxonomic composition from climatic pressures (Renaud et al. 2015).

\subsection{Functional diversity metrics}

Epibenthic communities on both shelves were overall functionally similar, as indicated by comparable FRic and FDiv. However, we also observed differences in functional dissimilarity (Rao's Q) between the epibenthos of the 2 shelf systems, which were driven by significant differences in FEve. Differences in FEve were reflected in the more even distribution of modalities for the influential biological traits of body form, body size, and larval development in the Beaufort Sea compared with the Chukchi Sea community. Differences in biological trait expressions within a community will lead to differences in which resources are used within each community (McGill et al. 2006, Cadotte et al. 2011). Higher FEve and lower functional redundancy (although not significantly lower functional redundancy) in the Beaufort Sea community pointed to the use of a wider range of available resources within their respective niche space (Mason et al. 2005). For example, resource breadth for epibenthic shelf communities differs for substrate and food type. Sediments on the narrow Beaufort Sea shelf are a poorly sorted mix of gravel, sands, and muds, controlled by variable currents, river discharge, and ice rafting (Naidu 1974). In contrast, sediments on the broader Chukchi Sea shelf tend to be more uniform over larger regions in accordance with larger current systems (Grebmeier et al. 2015). Also, the Beaufort Sea shelf contains a diverse range of carbon sources as possible food sources for the benthos, including large amounts of terrestrial organic material from massive river discharge, marine phytoplankton, microphytobenthos, ice algal production, and macroalgal stands in the coastal Beaufort Sea (Bell et al. 2016, Harris et al. 2018). In contrast, there are fewer sources of macroalgae and terrestrial material on the Chukchi shelf. The higher FEve on the Beaufort shelf affords more opportunities to exploit such wider resource availability. Higher FEve also reflects a strong potential for maintenance of ecosystem function with loss of species due to a high degree of niche complementarity (Hewitt et al. 2008). Greater niche complementarity usually leads to greater resource partitioning within communities (Finke \& Snyder 2008). In contrast, the lower FEve in the Chukchi Sea community pointed to lower niche complementarity and, thus, a potential underutilization of resources (Mason et al. 2005). Higher functional redundancy in the Chukchi Sea could also lead to underutilization of resources, and is expected to increase with increasing temperatures through the borealization of the Chukchi Sea (Alabia et al. 2020). This scenario could lead to a system that is more vulnerable to invading species that would be able to capitalize on those available, underutilized resources (Tilman 2001). This is of particular importance to an inflow shelf such as the Chukchi Sea shelf, which receives species that are increasingly migrating northward from the Bering Sea in response to continued warming (Mueter \& Litzow 2008, Stevenson \& Lauth 2019, Thorson et al. 2019, Alabia et al. 2020).

\subsection{Functional trait composition of Beaufort and Chukchi Sea epibenthos}

\subsubsection{Trait similarities between the shelves}

Composition of functional traits on the Beaufort and Chukchi Sea shelves was similar in many aspects, as demonstrated through similar proportions of modalities within 5 biological traits. Shared trait composition should support similar ecosystem functioning (Lavorel \& Garnier 2002). For example, benthic macrofaunal groups in the Baltic Sea clustered into groups based on shared biological trait composition that had similar effects on the ecosystem functions of stability and bioturbation (Villnäs et al. 2018, Liu et al. 2019). Similar modality composition between the Beaufort and Chukchi Sea shelves were seen in feeding habit, fragility, living habit, movement, and sociability. Many of these traits can be used to assess the vulnerability of benthic fauna to destructive forces and disturbances. Robustness of taxa, regeneration time, and position in the sediment have been used to assess benthic fauna vulnerable to disturbances such as the impact of predators (Weigel et al. 2016, Beauchard et al. 2017). Predator impacts may increase in Arctic shelf communities as ongoing and future habitat ranges of predatory species (e.g. Pacific and Atlantic cod) extend northward onto Arctic shelves (Rand \& Logerwell 2011, Alabia et al. 2020). Such impacts could be further amplified if commercial fisheries were to move north into the Chukchi Sea from the Bering Sea, following demersal fish migrations (Christiansen et al. 2014). One could expect that the Beaufort and Chukchi Sea shelf systems would 
respond in a similar way to those disturbances based on their similar composition of many functional traits.

Within the shared biological traits of feeding habit and movement, specifically, deposit feeding habit and crawling movement can have strong impacts on ecosystem services such as sediment oxygenation, resuspension, and remineralization through downward and horizontal movements of detrital particles (Snelgrove et al. 2000, Queirós et al. 2013). For example, brittle stars are a dominant taxon across the Beaufort and Chukchi Sea shelves (Ravelo et al. 2015, 2017, Iken et al. 2019), and the prominent species (Ophiocten sericeum and Ophiura sarsii, respectively) generally express a similar biological trait profile. They are mostly deposit feeders, have medium/robust fragility, free-living habits, burrowing and crawling movement types, and solitary life styles. These distinctive modalities in ophiuroids affect carbon and nutrient cycling in a similar way in both Arctic shelf systems through bioturbation (Kristensen 2000, Ambrose et al. 2001).

\subsubsection{Trait differences between the shelves}

Strong differences existed in modality composition in 4 biological traits between the Beaufort and Chukchi Sea shelves: larval development, reproductive strategy, body size, and body form. These traits, to varying degrees, have been observed to drive variation in benthic ecosystem function in the North Sea (Bolam \& Eggleton 2014) and the Arctic Ocean (Degen 2015, Kokarev et al. 2017, Rand et al. 2018). We suggest that these traits also contribute to differences in ecosystem functioning between the Beaufort and Chukchi Sea shelf communities.

The Chukchi Sea community had a higher proportion of planktotrophic larval development compared to the Beaufort Sea community. Planktotrophic larval development and a sexual-external reproductive strategy provide epibenthic taxa with the ability to spread fast and far, which increases their ability to resist or recover after a disturbance (Węsławski et al. 2011). Planktotrophic larvae can spend days to months in the plankton phase because of their need to feed during development (Thorson 1950, Pechenik 1990, Buzhinskaja 2006). This planktonic duration is inversely correlated with temperatures, leading to typically longer times spent in the plankton for Arctic larvae (O'Connor et al. 2007, Ershova et al. 2019) due to reduced metabolic rates compared to regions with warmer water temperatures (Gillooly et al. 2002). For example, planktotrophic larval development time of
2 common crustaceans, the shrimp Pandalus borealis and the hermit crab Pagurus bernhardus, followed predicted exponential increases in larval duration with decreased temperature (O'Connor et al. 2007). Long larval development times, coupled with strong, large-scale advection driving a strong injection of larvae from the Bering Sea to the Chukchi Sea shelf (Ershova et al. 2019), allow Arctic taxa to efficiently colonize open space across large distances in the Chukchi Sea. In contrast, the Beaufort Sea shelf community, which does not possess a similar source of advected larvae, had high proportions of lecithotrophic and direct development. These development types either spend no time (direct development) or little time (lecithotrophic development) in the plankton, indicating a high level of preservation of local ecosystem processes mediated by these low-dispersal traits (Degen \& Faulwetter 2019). These life history strategies may be an adaptation to the narrow Beaufort Sea shelf, likely reducing advective losses of larvae into unsuitable deep-sea habitats that could result from seasonally strong flow regimes (Pickart 2004). Also, direct or lecithotrophic development might be less affected by large-scale water column stressors. For example, high latitudes are particularly vulnerable to ocean acidification due to the naturally occurring low carbonate concentration derived from low water temperatures (Feely \& Chen 1982, Byrne et al. 2010). These acidic conditions can be particularly detrimental to many of the pelagic early life stages of invertebrates (Long et al. 2013a,b). Brooding species with direct development are likely less affected by ocean acidification due to maternal protection of the developing juveniles compared with species with planktotrophic larval development that spend extended time periods in those conditions (Lucey et al. 2015).

Body size has been referred to as the master or key trait because it affects numerous aspects of ecosystem functioning because of its many relationships with other traits (Degen et al. 2018). For example, body size is highly correlated with behavioral traits such as predatory feeding habits (Riede et al. 2010, Nordström et al. 2015), where largersized predators typically consume larger-sized prey (Riede et al. 2010). Indeed, we found a higher proportion of typical upper trophic level feeding habits (i.e. scavengers and predators) in the larger-sized Chukchi epibenthos.

Body size can also influence nutrient cycling and energy turnover through metabolic rates (Hall et al. 2009). Nutrient cycling can be directly regulated by organisms, for example, through input of nitrogen to 
a system via excretion and ingestion, and indirectly regulated through an organism's influence on microbial communities and primary production (Hall et al. 2009). In addition, communities with smaller-sized taxa (i.e. the Beaufort Sea community) will have a larger effect on energy turnover compared to those dominated by larger taxa, because smaller taxa have higher metabolic, excretion, and turnover rates (e.g. shorter generation time) (Pearson \& Rosenberg 1978, Brown et al. 2004). Larger mobile marine invertebrates such as in the Chukchi Sea are more likely to travel greater distances, which would move energy in the form of biomass across the shelves on a large scale, similar to the large-scale effects of dispersive larvae on ecosystem function discussed in this section. Higher metabolic, excretion, and turnover rates of smaller mobile invertebrates, coupled with smaller dispersal potential in the Beaufort Sea community, may retain energy more locally compared to the Chukchi Sea community. This essentially creates a system where taxa in the Beaufort Sea are more restricted to use the local resources available, where high FEve reflects more efficient use of all available resources by the functionally more dissimilar assemblages (high Rao's Q).

Body form is often related to ecological roles such as bioturbation and habitat formation that can lead to ecosystem stability (Degen \& Faulwetter 2019). Taxa with specific body forms can be vulnerable to common disturbances, which may destabilize ecosystem function (Jørgensen et al. 2015, 2019, Degen et al. 2018). For example, pressure from some predators or trawling will likely affect upright body forms more than vermiform or dorso-ventrally compressed body forms, because upright body forms have more above-ground exposure (Bremner et al. 2006, Jørgensen et al. 2019). Dorso-ventrally compressed body forms, in addition to vermiform body forms, increase bioturbation, which tends to foster ecosystem production and stability (Degen \& Faulwetter 2019). Body form is more closely related to taxonomic identity than most other traits, i.e. biological traits are assigned to taxa that are typically identified based on morphological features (Beauchard et al. 2017). This close relationship between body form and taxonomy makes body form a contentious trait to include in functional diversity analyses (Beauchard et al. 2017). The inclusion of this trait has advantages and disadvantages due to the strong relationships that exist between body form-related traits and the taxa present in a region, which gives taxonomy disproportional weight in functional analyses. In our study, we saw this relationship between dominant body forms and taxonomy in both shelf systems. For example, the Chukchi Sea epibenthos was mostly dominated by the dorso-ventrally compressed body form, which was reflected in the frequent and high biomass-contributing species such as Chionoecetes opilio, Echinarachnius parma, and Ophiura sarsii. In contrast, the Beaufort Sea epibenthos was dominated by globulose, dorso-ventrally compressed, and laterally compressed body forms, which were represented by the frequent biomass contributors Psolus peronii, Ophiocten sericeum, and Similipecten greenlandicus, respectively (note that $S$. greenlandicus and other bivalves were functionally coded as laterally compressed based on morphology, not necessarily reflecting their position on the seafloor). Although a tight relationship with taxonomy did exist, we considered the inclusion of body form necessary to glean information on community vulnerability to disturbances such as trawling. The Chukchi Sea shelf, which is directly north of the Bering Sea, will likely see increased commercial interest, but may be more resilient to this type of disturbance if the shelf remains dominated by taxa that are dorso-ventrally compressed.

\section{CONCLUSIONS}

The current benchmark of functional and taxonomic diversity metrics, and of functional and taxonomic composition, of Beaufort and Chukchi Sea epibenthic communities provided here will aid in future shelf-wide or among-shelf ecosystem function comparisons in the Alaskan Arctic. In the rapidly changing Arctic, these benchmarks will support interpretation of long-term monitoring data. Currently, differences in specific biological traits (e.g. body form, body size, larval development, reproductive strategy) lead to differences in ecosystem function between the Beaufort and Chukchi Sea epibenthic shelf communities. These differences mirror differences in taxonomic diversity, with the Beaufort Sea epibenthic community having significantly higher diversity. The combination of functional and taxonomic diversity metrics enables us to have a comprehensive understanding of how ecological niche space is currently used in Alaskan Arctic benthic shelf systems. Future studies should evaluate environmental influences on functional diversity, as well as on ecosystem function changes over time, and space so we can predict how the ecology of the Arctic benthos is likely to change. 
Acknowledgements. We thank Nora Foster, Ken Coyle, Max Hoberg (all UAF), Linda Cole, Chris Mah (both Smithsonian Institute), Gordon Hendler (Natural History Museum of Los Angeles County), Angelika Brandt (Senckenberg Society for Nature Research Frankfurt, Germany), and Roland Melzer (Ludwig-Maximilians-Universität Munich, Germany) for their taxonomic expertise. The crew and scientists aboard the AMBON 2015, ANIMIDA 2014, 2015, and Transboundary 2014 research cruises are appreciated for their hard work and dedication. We thank Brenda Konar and Claudine Hauri (UAF) for their comments on this manuscript as well as Renate Degen (University of Vienna) for her help and support with the Arctic Traits Database. This manuscript is a contribution to the US Marine Biodiversity Observation Network (MBON), the US Integrated Ocean Observing System, and the Group on Earth Observations Biodiversity Observation Network (GEO BON). The work was funded under the US National Oceanographic Partnership Program (NOPP) through NOAA award UAF NA14NOS0120158 Arctic Marine Biodiversity Observing Network (AMBON), with contributions from NOAA, the Bureau of Ocean Energy Management (BOEM), and Shell Exploration \& Production under management of the Integrated Ocean Observing System (IOOS). This work was also supported in part by the Coastal Marine Institute (M17AC00010) and is in part the result of research sponsored by the Cooperative Institute for Alaska Research with funds from NOAA under cooperative agreements NA13OAR4320056 and NA08OAR4320870 with the University of Alaska. This work was partially conducted under BOEM Cooperative Agreement No. M12AC00011 'US-Canada Transboundary Fish and Lower Trophic Communities,' US Department of the Interior, BOEM, Alaska Outer Continental Shelf Region, Anchorage, Alaska, as part of the BOEM Environmental Studies Program. Partial funding also was provided by the NOAA Arctic Research Program/Climate Program Office under the RUSALCA project (NA08OAR4320870). B.A.B. appreciates support from the Arctic SIZE project co-funded by the Tromsø Research Foundation and UiT The Arctic University of Norway $(01 \mathrm{vm} / \mathrm{h} 15)$. We thank 3 anonymous reviewers for their suggestions and comments.

\section{LITERATURE CITED}

Alabia ID, García J, Saitoh S, Hirata T, Hirawake T, Mueter FJ (2020) Multiple facets of marine biodiversity in the Pacific Arctic under future climate. Sci Total Environ 744:140913

Ambrose W, Clough L, Tilney P, Beer L (2001) Role of echinoderms in benthic remineralization in the Chukchi Sea. Mar Biol 139:937-949

Arrigo KR, van Dijken GL (2015) Continued increases in Arctic Ocean primary production. Prog Oceanogr 136:60-70

* Beauchard O, Veríssimo H, Queirós AM, Herman PMJ (2017) The use of multiple biological traits in marine community ecology and its potential in ecological indicator development. Ecol Indic 76:81-96

* Bell LE, Bluhm BA, Iken K (2016) Influence of terrestrial organic matter in marine food webs of the Beaufort Sea shelf and slope. Mar Ecol Prog Ser 550:1-24

Bellwood DR, Streit RP, Brandl SJ, Tebbett SB (2019) The meaning of the term 'function' in ecology: a coral reef perspective. Funct Ecol 33:948-961
Blanchard AL, Parris CL, Knowlton AL, Wade NR (2013) Benthic ecology of the northeastern Chukchi Sea. II. Spatial variation of megafaunal community structure, 2009-2010. Cont Shelf Res 67:67-76

* Bluhm BA, Iken K, Mincks Hardy S, Sirenko BI, Holladay BA (2009) Community structure of epibenthic megafauna in the Chukchi Sea. Aquat Biol 7:269-293

Bolam SG, Eggleton JD (2014) Macrofaunal production and biological traits: spatial relationships along the UK continental shelf. J Sea Res 88:47-58

Bremner J, Rogers SI, Frid CLJ (2006) Methods for describing ecological functioning of marine benthic assemblages using biological traits analysis (BTA). Ecol Indic 6: 609-622

* Brown JH, Gillooly JF, Allen AP, Savage VM, West GB (2004) Toward a metabolic theory of ecology. Ecology 85: 1771-1789

Buzhinskaja GN (2006) Ecology of reproduction of shallow water benthic polychaetes in high latitude Arctic seas. Proc Zool Inst Russ Acad Sci 310:25-34

Byrne RH, Mecking S, Feely RA, Liu X (2010) Direct observations of basin-wide acidification of the North Pacific Ocean. Geophys Res Lett 37:L02601

Cadotte MW, Carscadden K, Mirotchnick N (2011) Beyond species: functional diversity and the maintenance of ecological processes and services. J Appl Ecol 48: 1079-1087

* Cardinale B, Duffy E, Srivastava D, Loreau M, Thomas M, Emmerson M (2009) Towards a food web perspective on biodiversity and ecosystem functioning. In: Naeem $\mathrm{S}$, Bunker DE, Hector A, Loreau M, Perrings C (eds) Biodiversity, ecosystem functioning, and human wellbeing. Oxford University Press, Oxford Scholarship Online, p 583-605

* Cardinale BJ, Duffy JE, Gonzalez A, Hooper DU and others (2012) Biodiversity loss and its impacts on humanity. Nature 486:59-67

Carmack E, Wassmann P (2006) Food webs and physicalbiological coupling on pan-Arctic shelves: unifying concepts and comprehensive perspectives. Prog Oceanogr 71:446-477

Carmack EC, Yamamoto-Kawai M, Haine TWN, Bacon S and others (2016) Freshwater and its role in the Arctic Marine System: sources, disposition, storage, export, and physical and biogeochemical consequences in the Arctic and global oceans. J Geophys Res Biogeosci 121: $675-717$

Carmona CP, de Bello F, Mason NWH, Leps J (2016) Traits without borders: integrating functional diversity across scales. Trends Ecol Evol 31:382-394

Chevenet F, Dolédec S, Chessel D (1994) A fuzzy coding approach for the analysis of long-term ecological data. Freshw Biol 31:295-309

Christiansen JS, Mecklenburg CW, Karamushko OV (2014) Arctic marine fishes and their fisheries in light of global change. Glob Change Biol 20:352-359

Clarke KR, Gorley RN (2015) PRIMER v7: user manual/ tutorial. PRIMER-E, Plymouth

Clarke KR, Warwick RM (1994) Change in marine communities: an approach to statistical analysis and interpretation. Plymouth Marine Laboratory, Plymouth

Conti L, Schmidt-Kloiber A, Grenouillet G, Graf W (2014) A trait-based approach to assess the vulnerability of European aquatic insects to climate change. Hydrobiologia 721:297-315 
de Bello F, Carmona CP, Lepš J, Szava-Kovats R, Pärtel M (2016) Functional diversity through the mean trait dissimilarity: resolving shortcomings with existing paradigms and algorithms. Oecologia 180:933-940

Degen R (2015) The future Arctic biosphere. PhD dissertation, Universität Bremen

* Degen R, Faulwetter S (2019) The Arctic Traits Databasea repository of arctic benthic invertebrate traits. Earth Syst Sci Data 11:301-322

Degen R, Aune M, Bluhm BA, Cassidy C and others (2018) Trait-based approaches in rapidly changing ecosystems: a roadmap to the future polar oceans. Ecol Indic 91: 722-736

* Díaz S, Cabido M (2001) Vive la différence: Plant functional diversity matters to ecosystem processes. Trends Ecol Evol 16:646-655

Divine LM, Iken K, Bluhm BA (2015) Regional benthic food web structure on the Alaska Beaufort Sea shelf. Mar Ecol Prog Ser 531:15-32

Divine LM, Bluhm BA, Mueter FJ, Iken K (2017) Diet analysis of Alaska Arctic snow crabs (Chionoecetes opilio) using stomach contents and $\delta^{13} \mathrm{C}$ and $\delta^{15} \mathrm{~N}$ stable isotopes. Deep Sea Res II 135:124-136

Ershova E, Descoteaux R, Wangensteen OS, Iken K and others (2019) Diversity and distribution of meroplanktonic larvae in the Pacific Arctic and connectivity with adult benthic invertebrate communities. Front Mar Sci 6:490

Fay FH (1982) Ecology and biology of the Pacific walrus, Odobenus rosmarus divergens Illiger. N Am Fauna 74: 1-279

Feely RA, Chen CA (1982) The effect of excess $\mathrm{CO}_{2}$ on the calculated calcite and aragonite saturation horizons in the Northeast Pacific. Geophys Res Lett 9:1294-1297

Finke DL, Snyder WE (2008) Niche partitioning increases resource exploitation by diverse communities. Science 321:1488-1490

Frey KE, Comiso JC, Cooper LW, Grebmeier JM, Stock LV (2019) Arctic Ocean primary productivity: the response of marine algae to climate warming and sea ice decline. Arctic Report Card 2019. https://arctic.noaa.gov/ReportCard/Report-Card-2019/ArtMID/7916/ArticleID/839/ Arctic-Ocean-Primary-Productivity-The-Response-ofMarine-Algae-to-Climate-Warming-and-Sea-Ice-Decline

Garnier E, Lavorel S, Ansquer P, Castro H and others (2007) Assessing the effects of land-use change on plant traits, communities and ecosystem functioning in grasslands: a standardized methodology and lessons from an application to 11 European sites. Ann Bot 99:967-985

Gillooly JF, Charnov EL, West GB, Savage VM, Brown JH (2002) Effects of size and temperature on developmental time. Nature 417:70-73

Grebmeier JM, Maslowski J (eds) (2014) The Pacific Arctic region ecosystem status and trends in a rapidly changing environment. Springer, New York, NY

* Grebmeier JM, Cooper L, Feder H, Sirenko B (2006) Ecosystem dynamics of the Pacific-influenced Northern Bering and Chukchi Seas in the Amerasian Arctic. Prog Oceanogr 71:331-361

Grebmeier JM, Cooper LW, Ashjian CA, Bluhm BA and others (2015) Pacific Marine Arctic Regional Synthesis (PacMARS) Final Report. North Pacific Research Board. http:// pacmars.cbl.umces.edu/

Gunderson DR, Ellis IE (1986) Development of a plumb staff beam trawl for sampling demersal fauna. Fish Res 4: $35-41$
Hall ROJ, Koch BJ, Marshall MC, Taylor BW, Tronstad LM (2009) How body size mediates the role of animals in nutrient cycling in aquatic ecosystems. In: Hidrew AG, Raffaelli DG, Edmonds-Brown R (eds) Body size: the structure and function of aquatic ecosystems. Cambridge University Press, New York, NY, p 286-305

*Harris CM, McTigue ND, McClelland JW, Dunton KH (2018) Do high Arctic coastal food webs rely on a terrestrial carbon subsidy? Food Webs 15:e00081

* Hewitt JE, Thrush SF, Dayton PD (2008) Habitat variation, species diversity and ecological functioning in a marine system. J Exp Mar Biol Ecol 366:116-122

KHill VJ, Matrai PA, Olson E, Suttles S, Steele M, Codispoti LA, Zimmerman RC (2013) Synthesis of integrated primary production in the Arctic Ocean. II. In situ and remotely sensed estimates. Prog Oceanogr 110:107-125

*Hill V, Ardyna M, Lee SH, Varela DE (2018) Decadal trends in phytoplankton production in the Pacific Arctic Region from 1950 to 2012. Deep Sea Res II 152:82-94

*Huntington HP, Danielson SL, Wiese FK, Baker M and others (2020) Evidence suggests potential transformation of the Pacific Arctic ecosystem is underway. Nat Clim Change 10:342-348

Iken K, Bluhm B, Dunton K (2010) Benthic food-web structure under differing water mass properties in the southern Chukchi Sea. Deep Sea Res II 57:71-85

* Iken K, Mueter F, Grebmeier JM, Cooper LW, Danielson SL, Bluhm BA (2019) Developing an observational design for epibenthos and fish assemblages in the Chukchi Sea. Deep Sea Res II 162:180-190

Jørgensen LL, Ljubin P, Skjoldal HR, Ingvaldsen RB, Anisimova N, Manushin I (2015) Distribution of benthic megafauna in the Barents Sea: baseline for an ecosystem approach to management. ICES J Mar Sci 72:595-613

* Jørgensen LL, Primicerio R, Ingvaldsen RB, Fossheim M and others (2019) Impact of multiple stressors on sea bed fauna in a warming Arctic. Mar Ecol Prog Ser 608: $1-12$

Kembel SW, Cowan PD, Helmus MR, Cornwell WK and others (2010) Picante: R tools for integrating phylogenies and ecology. Bioinformatics 26:1463-1464

Kokarev VN, Vedenin AA, Basin AB, Azovsky AI (2017) Taxonomic and functional patterns of macrobenthic communities on a high-Arctic shelf: a case study from the Laptev Sea. J Sea Res 129:61-69

Kristensen E (2000) Organic matter diagenesis at the oxic/ anoxic interface in coastal marine sediments, with the emphasis on the role of burrowing animals. Hydrobiologia 426:1-24

K Krumhansl K, Jamieson R, Krkosek W (2016) Using species traits to assess human impacts on near shore benthic ecosystems in the Canadian Arctic. Ecol Indic 60:495-502

* Laliberté E, Legendre P (2010) A distance-based framework for measuring functional diversity from multiple traits. Ecology 91:299-305

KLavorel S, Garnier E (2002) Predicting changes in community composition and ecosystem functioning from plant traits: revisiting the Holy Grail. Funct Ecol 16:545-556

* Liu K, Lin H, He X, Huang Y and others (2019) Functional trait composition and diversity patterns of marine macrobenthos across the Arctic Bering Sea. Ecol Indic 102: 673-685

Long WC, Swiney KM, Foy RJ (2013a) Effects of ocean acidification on the embryos and larvae of red king crab, Paralithodes camtschaticus. Mar Pollut Bull 69:38-47 
Long WC, Swiney KM, Harris C, Page HN, Foy RJ (2013b) Effects of ocean acidification on juvenile red king crab (Paralithodes camtschaticus) and Tanner crab (Chionoecetes bairdi) growth, condition, calcification, and survival. PLOS ONE 8:e60959

Loreau M, Naeem S, Inchausti P, Bengtsson J and others (2001) Biodiversity and ecosystem functioning: current knowledge and future challenges. Science 294:804-808

Lovvorn JR, Richman SE, Grebmeier JM, Cooper LW (2003) Diet and body condition of spectacled eiders wintering in pack ice of the Bering Sea. Polar Biol 26:259-267

Lucey NM, Lombardi C, Demarchi L, Schulze A, Gambi MC, Calosi P (2015) To brood or not to brood: Are marine invertebrates that protect their offspring more resilient to ocean acidification? Sci Rep 5:12009

Magurran AE (2004) Measuring biological diversity. Blackwell Publishing, Malden, MA

Mason NWH, Mouillot D, Lee WG, Wilson JB (2005) Functional richness, functional evenness and functional divergence: the primary components of functional diversity. Oikos 111:112-118

McGill BJ, Enquist BJ, Weiher E, Westoby M (2006) Rebuilding community ecology from functional traits. Trends Ecol Evol 21:178-185

Mouchet MA, Villéger S, Mason NWH, Mouillot D (2010) Functional diversity measures: an overview of their redundancy and their ability to discriminate community assembly rules. Funct Ecol 24:867-876

Mueter FJ, Litzow MA (2008) Sea ice retreat alters the biogeography of the Bering Sea continental shelf. Ecol Appl 18:309-320

Naeem S, Thompson LJ, Lawler SP, Lawton JH, Woodfin RM (1994) Declining biodiversity can alter the performance of ecosystems. Nature 368:734-737

Naidu AS (1974) Sedimentation in the Beaufort Sea: a synthesis. In: Herman Y (ed) Marine geology and oceanography of the Arctic Seas. Springer, Berlin, p 173-190

Nordström MC, Aarnio K, Tornroos A, Bonsdorff E (2015) Nestedness of trophic links and biological traits in a marine food web. Ecosphere 6:161

* $\mathrm{O}^{\prime}$ Connor MI, Bruno JF, Gaines SD, Halpern BS, Lester SE, Kinlan BP, Weiss JM (2007) Temperature control of larval dispersal and the implications for marine ecology, evolution, and conservation. Proc Natl Acad Sci USA 104: 1266-1271

Oksanen J, Blanchet FG, Friendly M, Kindt R and others (2019) Vegan: community ecology package. R package version 2.5-6. https://CRAN.R-project.org/package=vegan

Oliver JS, Slattery PN, O'Connor EF, Lowry LF (1983) Walrus, Odobenus rosmarus, feeding in the Bering Sea: a benthic perspective. Fish Bull 81:501-512

Pearson TH, Rosenberg R (1978) Macrobenthic succession in relation to organic enrichment and pollution of the marine environment. Oceanogr Mar Biol Annu Rev 16: 229-311

Pechenik JA (1990) Delayed metamorphosis by larvae of benthic marine invertebrates: Does it occur? Is there a price to pay? Ophelia 32:63-94

Petchey OL, Gaston KJ (2006) Functional diversity: back to basics and looking forward. Ecol Lett 9:741-758

"Pickart RS (2004) Shelfbreak circulation in the Alaskan Beaufort Sea: mean structure and variability. J Geophys Res 109:C04024

Pielou EC (1975) Ecological diversity. Wiley, New York, NY Pinheiro J, Bates D, DebRoy S, Sarkar D, R Core Team
(2020) nlme: linear and nonlinear mixed effects models. R package version 3.1-148. https://CRAN.R-project.org/ package $=$ nlme

* Queirós AM, Birchenough SNR, Bremner J, Godbold JA, Parker RE, Widdicombe S (2013) A bioturbation classification of European marine infaunal invertebrates. Ecol Evol 3:3958-3985

R Core Team (2020) R: a language and environment for statistical computing, Version 4.0.2. R Foundation for Statistical Computing, Vienna

Rand KM, Logerwell EA (2011) The first demersal trawl survey of benthic fish and invertebrates in the Beaufort Sea since the late 1970s. Polar Biol 34:475-488

* Rand K, Logerwell E, Bluhm B, Chenelot H, Danielson S, Iken K, Sousa L (2018) Using biological traits and environmental variables to characterize two Arctic epibenthic invertebrate communities in and adjacent to Barrow Canyon. Deep Sea Res II 152:154-169

Rao CR (1982) Diversity and dissimilarity coefficients: a unified approach. Theor Popul Biol 21:24-43

Ravelo AM, Konar B, Trefry JH, Grebmeier JM (2014) Epibenthic community variability in the northeastern Chukchi Sea. Deep Sea Res II 102:119-131

Ravelo AM, Konar B, Bluhm BA (2015) Spatial variability of epibenthic communities on the Alaska Beaufort Shelf. Polar Biol 38:1783-1804

* Ravelo AM, Konar B, Bluhm B, Iken K (2017) Growth and production of the brittle stars Ophiura sarsii and Ophiocten sericeum (Echinodermata: Ophiuroidea). Cont Shelf Res 139:9-20

Ravelo AM, Bluhm BA, Foster N, Iken K (2020) Biogeography of epibenthic assemblages in the central Beaufort Sea. Mar Biodivers 50:8

* Renaud PE, Sejr MK, Bluhm BA, Sirenko B, Ellingsen IH (2015) The future of Arctic benthos: expansion, invasion, and biodiversity. Prog Oceanogr 139:244-257

* Renaud PE, Wallhead P, Kotta J, Włodarska-Kowalczuk M and others (2019) Arctic sensitivity? Suitable habitat for benthic taxa is surprisingly robust to climate change. Front Mar Sci 6:538

* Ricotta C, de Bello F, Moretti M, Caccianiga M, Cerabolini BEL, Pavoine S (2016) Measuring the functional redundancy of biological communities: a quantitative guide. Methods Ecol Evol 7:1386-1395

* Riede JO, Rall BC, Banasek-Richter C, Navarrete SA and others (2010) Scaling of food-web properties with diversity and complexity across ecosystems. Adv Ecol Res 42: $139-170$

Rosenfeld JS (2002) Functional redundancy in ecology and conservation. Oikos 98:156-162

Sakshaug E (2004) Primary and secondary production in the Arctic Seas. In: Stein R, MacDonald RW (eds) The organic carbon cycle in the Arctic Ocean. Springer, Berlin, p 57-81

Schleuter D, Daufresne M, Massol F, Argillier AC (2010) A user's guide to functional diversity indices. Ecol Monogr 80:469-484

Shannon CE (1948) A mathematical theory of communication. Bell Syst Tech J 27:379-423

* Simpson E (1949) Measurement of diversity. Nature 163:688

* Snelgrove PVR, Austen MC, Boucher G, Heip C and others (2000) Linking biodiversity above and below the marine sediment-water interface. Bioscience 50:1076-1088

Stevenson DE, Lauth RR (2019) Bottom trawl surveys in the northern Bering Sea indicate recent shifts in the distribution of marine species. Polar Biol 42:407-421 
Stroeve JC, Serreze MC, Holland MM, Kay JE, Malanik J, Barrett AP (2012) The Arctic's rapidly shrinking sea ice cover: a research synthesis. Clim Change 110: 1005-1027

Thorson G (1950) Reproduction and larval ecology of marine bottom invertebrates. Biol Rev Camb Philos Soc 25:1-45

Thorson JT, Fossheim M, Mueter FJ, Olsen E and others (2019) Comparison of near-bottom fish densities show rapid community and population shifts in Bering and Barents Seas. Arctic Report Card 2019. https://arctic.noaa. gov/Report-Card/Report-Card-2019/ArtMID/7916/ ArticleID/845/Comparison-of-Near-bottom-Fish-DensitiesShow-Rapid-Community-and-Population-Shifts-in-Beringand-Barents-Seas

Tilman D (2001) Functional diversity. In: Levin SA (ed) Encyclopedia of biodiversity. Academic Press, Cambridge, MA p 109-120

Villéger S, Mason H, Mouillot D (2008) New multidimensional functional diversity indices for a multifaceted framework in functional ecology. Ecology 89:2290-2301

Editorial responsibility: Stephen Wing,

Dunedin, New Zealand
Villnäs A, Hewitt J, Snickars M, Westerbom M, Norkko A (2018) Template for using biological trait groupings when exploring large-scale variation in seafloor multifunctionality. Ecol Appl 28:78-94

Waga H, Hirawake T, Grebmeier JM (2020) Recent change in benthic macrofaunal community composition in relation to physical forcing in the Pacific Arctic. Polar Biol 43: 285-294

* Weigel B, Blenckner T, Bonsdorff E (2016) Maintained functional diversity in benthic communities in spite of diverging functional identities. Oikos 125:1421-1433

* Węsławski JM, Kendall MA, Włodarska-Kowalczuk M, Iken K, Kędra M, Legezynska J, Sejr MK (2011) Climate change effects on Arctic fjord and coastal macrobenthic diversity - observations and predictions. Mar Biodivers 41:71-85

*Whitehouse GA, Buckley TW, Danielson SL (2017) Diet compositions and trophic guild structure of the eastern Chukchi Sea demersal fish community. Deep Sea Res II 135:95-110

Submitted: April 21, 2020; Accepted: August 21, 2020 Proofs received from author(s): September 24, 2020 